\title{
A Lagrangian relaxation approach to simultaneous strategic and tactical planning in supply chain design
}

\author{
Ali Diabat · Jean-Philippe Richard • \\ Craig W. Codrington
}

Published online: 9 July 2011

(C) The Author(s) 2011. This article is published with open access at Springerlink.com

\begin{abstract}
We study a multi-echelon joint inventory-location model that simultaneously determines the location of warehouses and inventory policies at the warehouses and retailers. The model is formulated as a nonlinear mixed-integer program, and is solved using a Lagrangian relaxation-based approach. The efficiency of the algorithm and benefits of integration are evaluated through a computational study.
\end{abstract}

Keywords Supply chain management · Facility location · Joint inventory-location · Lagrangian relaxation

\section{Introduction}

Two important considerations that arise in supply chain design are facility location and inventory management. Facility location decisions impact the firm over a significantly longer time scale than inventory management decisions; hence the former are regarded as strategic level decisions, whereas the latter are regarded as tactical level decisions. Facility location decisions and inventory management decisions are interrelated in the sense that a change in the location or number of warehouses can affect lead times and thereby affect inventoryrelated costs, and likewise a change in warehouse or retailer inventory policy can affect assignment decisions and thereby affect location-related costs. However, supply chain design

\footnotetext{
A. Diabat $(\bowtie)$

Engineering Systems and Management, Masdar Institute of Science and Technology, P.O. Box 54224, Abu Dhabi, United Arab Emirates

e-mail: adiabat@masdar.ac.ae

J.-P. Richard

Industrial and Systems Engineering, University of Florida, Gainesville, FL 32611-6595, USA

e-mail: richard@ise.ufl.edu

C.W. Codrington

Masdar Institute of Science and Technology, P.O. Box 54224, Abu Dhabi, United Arab Emirates

e-mail: ccodrington@masdar.ac.ae
} 
has traditionally considered facility location decisions and inventory management decisions independently, leading to excess costs because the supply chain is managed sub-optimally (Cavinato 1992; Chopra and Meindl 2006; Gunasekaran et al. 2001, 2004; Silver et al. 1998; Simchi-Levi et al. 2007; Stevens 1993).

In this paper we study a model that addresses these concerns by simultaneously determining the locations of warehouses and the inventory policies at the warehouses and retailers so as to minimize system-wide costs, and we develop a Lagrangian relaxation-based heuristic approach to solving it. Much of the previous work on joint inventory-location models considered the inventory policy at warehouses, but not at retailers. However, there have been a few exceptions: You and Grossman (2010), Romeijn et al. (2007), Teo and Shu (2004), and Shu (2010) all consider the inventory policy of the retailers in their joint inventory-location models. There are, however, important differences between our work and these previous works: our inventory policy uses an Economic Order Quantity (EOQ) formulation, whereas You and Grossman formulate their inventory policy in terms of guaranteed service levels; we solve our model using a Lagrangian relaxation approach, whereas Romeijn et al. (2007), Teo and Shu (2004), and Shu (2010) solve their models by formulating them as set-covering problems.

This paper is organized as follows. In Sect. 2, we review the literature on joint inventorylocation models. In Sect. 3 we describe the Multi-echelon Joint Inventory-Location (MJIL) problem. In Sect. 4 we describe a Lagrangian relaxation-based heuristic approach to solving the MJIL problem. In Sect. 5, we evaluate the effectiveness and efficiency of our algorithm through a computational study. Finally, in Sect. 6 we summarize our results and discuss future research directions.

\section{Literature review}

The literature on supply chain network design has traditionally considered facility location decisions and inventory management decisions independently: Amiri (2006), Daskin et al. (2005), Hindi and Pienkosz (1999), Pirkul and Jayaraman (1998), and Tsiakis et al. (2001) focus on location decisions, while Axsäter (2004), Jones and Riley (1987), Muckstadt and Roundy (1987), Svoronos and Zipkin (1991), and Wee and Yang (2004) focus on inventory management decisions.

Only recently have models that integrate these decisions been investigated. Barahona and Jensen (1998) integrate an economic order quantity (EOQ) inventory model with a location model, formulated as a large-scale integer program, and solve its linear programming relaxation using Dantzig-Wolfe decomposition. Erlebacher and Meller (2000) study an analytical joint location-inventory model that considers the fixed costs of operating warehouses, inventory holding costs at the warehouses, and transportation costs, and develop heuristic procedures to solve it. Teo et al. (2001) use an analytical modeling approach to study the impact on facility investments and inventory costs of consolidating warehouses; their model suggests that consolidation reduces costs when demands are independent and identically distributed or are independent and Poisson distributed. Miranda and Garrido (2006) propose a joint inventory-location model featuring two capacity constraints: a limit on the lot size for orders received from the warehouse, and a stochastic bound on the inventory capacity of warehouses; they solve their model using Lagrangian relaxation in conjunction with subgradient optimization.

Daskin et al. (2002) and Shen et al. (2003) study a location-inventory model with risk pooling (Eppen 1979). Daskin et al. (2002) formulate the problem as a mixed-integer nonlinear program, and, for the special case in which the ratio of the variance of demand to 
the mean of demand is identical for all retailers, solve the problem using a Lagrangian relaxation approach. Shen et al. (2003) formulate the problem as a set-covering problem, and solve the resulting problem using a column generation approach for two special cases: (i) the case in which the ratio of the variance of the demand to the mean of the demand is identical for all retailers, and (ii) the case in which the variance of the demand at each retailer is zero. There has been considerable effort devoted to extending the applicability of this model and to improving the associated solution procedures. Such extensions include the introduction of capacity constraints (Ozsen et al. 2008), assuming a specific functional form for the lead time (Sourirajan et al. 2007, 2009), stochastic lead times (Tanonkou et al. 2008), and relaxing the constraint that the variance-to-mean ratio of the random demands at each retailer are identical (Shu et al. 2005; Tanonkou et al. 2008; You and Grossman 2008).

There has been increasing interest in multi-echelon location-inventory models that consider inventory policy not only at warehouses, but also at retailers. You and Grossman (2010) propose a multi-echelon location-inventory model that considers location and periodic review inventory decisions simultaneously. Their formulation uses a guaranteed service level model to manage inventory at each retailer and at each warehouse, and also incorporates risk pooling at the warehouses. Romeijn et al. (2007) propose a generic modeling framework for two-echelon supply chains that considers location-specific costs, inventory costs at warehouses and retailers, and safety stock costs; by formulating their model as a set-covering problem, they obtain an efficient solution algorithm based on column generation. Teo and Shu (2004), and Shu (2010) also consider inventory policy at the retailer level in their joint inventory-location models, which are solved using a set-covering formulation.

\section{Description and formulation of the problem}

The multi-echelon joint inventory-location problem deals with the distribution of a single commodity from a single manufacturer to a set of retailers $I$ (indexed by $i$ ) through a set of warehouses that can be located at various predetermined sites (indexed by $j$ ), where $J$ is the set of possible sites. The retailers face deterministic demands and hold working inventory, representing product that has been ordered from a warehouse but has not yet been requested by end-customers. The warehouses order a single commodity from the manufacturer at regular intervals and distribute the product to the retailers. The warehouses hold working inventory representing product that has been ordered from the manufacturer but has not been yet requested by the retailers. Lateral supply among the warehouses is not allowed, that is, warehouses are supplied only by the manufacturer, and shortages are not allowed. Lead times are assumed to be negligible, although this restriction can easily be lifted to allow fixed lead times without significant changes to the model. The four major cost components in the system are:

- fixed order cost: the cost of placing an order regardless of the size of the order,

- unit-inventory cost: the cost of holding one unit of product for one unit of time,

- unit-shipping cost: the cost of shipping one unit of product between facilities, and

- fixed location cost: the cost of establishing and operating a warehouse.

The objective is to determine: (i) the number of warehouses to establish; (ii) their location; (iii) the sets of retailers that are assigned to each warehouse; and (iv) and the size and timing of orders for each facility, so as to minimize the sum of inventory, shipping, ordering, and location costs, while satisfying end-customer demand. 
It has been shown for the one-warehouse multi-retailer inventory problem that if an optimal solution exists, then an optimal solution can be found that satisfies the following three properties (Roundy 1985; Schwarz 1973):

- Zero-Inventory Ordering: Each warehouse or retailer orders only when its inventory level reaches zero (Schwarz 1973).

- Last-Minute Ordering: The warehouse orders only when at least one of the retailers orders.

- Stationarity-Between-Orders: For each retailer, the order quantities are identical for all orders placed between two successive orders at the warehouse.

For the multi-warehouse, multi-retailer inventory problem we are considering, it is unknown if the existence of an optimal solution implies that the above three properties hold. To simplify the problem, we assume single-sourcing, in which each retailer is served by exactly one warehouse; under this assumption, for a fixed assignment of retailers to warehouses, the problem decomposes into independent one-warehouse multi-retailer problems, each of which has an optimal solution satisfying the above three properties (if an optimal solution exists at all).

In view of the above, the Stationarity-Between-Orders property suggests that it may be reasonable to assume that the orders placed by a given retailer have identical sizes, which suggests that a natural inventory policy to assume at the retailers is an Economic Order Quantity (EOQ) policy, which features a fixed order size for each retailer. Furthermore, by making use of the notion of system inventory, we can treat the demand at each warehouse as constant, which suggests that an EOQ inventory policy may be appropriate for the warehouses as well. We therefore assume an EOQ inventory policy at the warehouses and at the retailers. The EOQ inventory policy has the advantages that it is simple to implement, is widely used, and tends to work well in practice.

The problem we are considering is a generalization of the one-warehouse multi-retailer inventory problem, in that we are also considering multiple warehouses and the assignment of retailers to warehouses. Given that even the one-warehouse multi-retailer inventory problem is difficult to solve to optimality (Roundy 1985), we must make some simplifying assumptions. We therefore assume power-of-two inventory policies, which have the desirable property of being $98 \%$ effective for the one-warehouse multi-retailer problem (Roundy 1985), meaning that the ratio of the average cost of the best policy to the average cost of the power-of-two policy is at least 0.98 . We will show later that a power-of-two inventory policy is also $98 \%$ effective for our problem, for a fixed assignment of retailers to warehouses.

A power-of-two inventory policy is one in which the ratio of the time between orders at the warehouse to the time between orders at each retailer it serves is a power of two. Let $\widehat{T}_{j}$ be the time between orders placed by warehouse $j$ to the plant, and let $T_{i j}$ be the time between orders placed by retailer $i$ to warehouse $j$ (assuming that retailer $i$ is served by warehouse $j$ ). Then, assuming a power-of-two inventory policy,

$$
\widehat{T}_{j} / T_{i j}=2^{N_{i j}}
$$

where $N_{i j} \in \mathbb{Z}$ for all $i, j$. We assume that $\widehat{T}_{j}$ and $T_{i j}$ are given in days.

Consider now the inventory problem faced by a single warehouse $j$ and the retailers it serves. Let $\mathfrak{\Im}_{j}$ be the set of retailers served by warehouse $j$, and let $\hat{h}_{j}, \hat{o}_{j}$ be respectively the unit-inventory holding cost per unit time at warehouse $j$, and the fixed cost per order at warehouse $j$. Let $h_{i}, o_{i}$ be respectively the unit-inventory holding cost per unit time at retailer $i$, and the fixed cost per order at retailer $i$. Since the number of orders placed by 


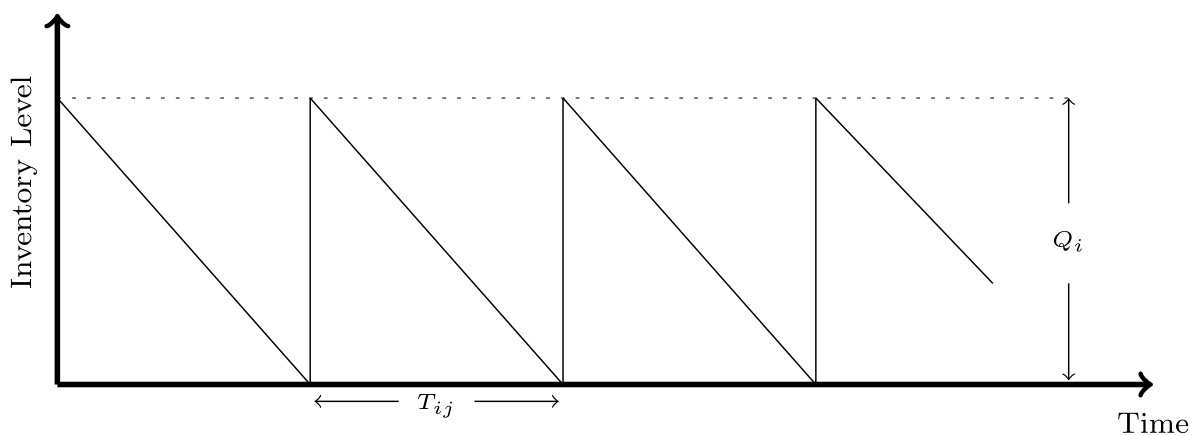

Fig. 1 An inventory-time plot for retailer $i$

warehouse $j$ to the plant per base planning period is $t_{b} / \widehat{T}_{j}$, and the cost per order is $\hat{o}_{j}$, the ordering cost per base planning period at warehouse $j$ is $\hat{o}_{j} t_{b} / \widehat{T}_{j}$. Let $\hat{C}_{j}$ denote the total inventory and ordering costs over the base planning period for the system composed of warehouse $j$ and the retailers it serves. Then $\hat{C}_{j}$, which is a function of $\widehat{T}_{j}$ and $\left\{T_{i j}: i \in \mathfrak{\Im}_{j}\right\}$, has the form

$$
\hat{C}_{j}\left(\widehat{T}_{j},\left\{T_{i j}: i \in \widetilde{\Im}_{j}\right\}\right)=\frac{\hat{o}_{j}}{\widehat{T}_{j}} t_{b}+\sum_{i \in \Im_{j}} C_{i j}\left(\widehat{T}_{j}, T_{i j}\right)
$$

where $C_{i j}$ represents the inventory and ordering costs imputable to retailer $i$. We next derive an explicit form for $C_{i j}$. Consider $\widehat{T}_{j}$ as fixed. Then the retailers $i$ fall into two groups: those for which $T_{i j} \leq \widehat{T}_{j}$, and those for which $T_{i j}>\widehat{T}_{j}$.

Case 1: $T_{i j}>\widehat{T}_{j}$ In this case, the warehouse places an order simultaneously with every order placed by retailer $i$, hence the warehouse will not carry an inventory of goods to be shipped to retailer $i$. It follows that the inventory cost at the warehouse for goods to be shipped to retailer $i$ is zero. We next determine the inventory and ordering costs at retailer $i$. Let $Q_{i}$ be the order quantity for retailer $i$ and $T_{i j}$ be the length of an order cycle for retailer $i$ (assumed to have units of days). Under our assumptions, the demand at retailer $i$ has the characteristic sawtooth pattern shown in Fig. 1. The average inventory level at retailer $i$ is the area under the time-inventory plot for one order cycle, or $\frac{1}{2} Q_{i} T_{i j}$, divided by the order cycle length $T_{i j}$, or $\frac{1}{2} Q_{i}$. Because the daily demand $d_{i}$ is constant, it follows from our assumptions that

$$
Q_{i}=d_{i} T_{i j}
$$

so that the average inventory level at retailer $i$ is

$$
\operatorname{AvgInv}_{i}=\frac{1}{2} \underbrace{Q_{i}}_{d_{i} T_{i j}}=\frac{1}{2} d_{i} T_{i j}
$$

Then the total inventory holding cost at retailer $i$ over the base planning period is the holding cost per unit per day, $h_{i}$, multiplied by the average daily inventory level at re- 


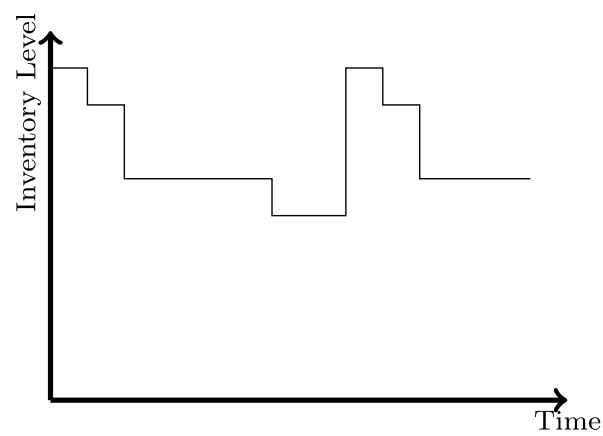

(a)

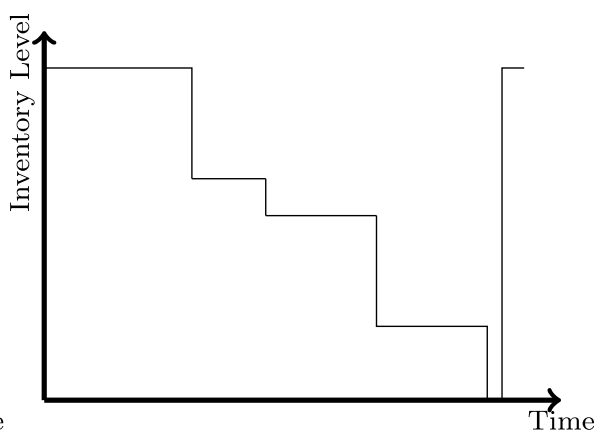

(b)

Fig. 2 Two possible inventory-time plots for warehouse $j$

tailer $i$, multiplied by the number of days per base planning period, $t_{b}$, so that

$$
\begin{aligned}
\text { TotalHoldingCost }_{i} & =h_{i} \cdot \underbrace{\operatorname{AvgInv}_{i}}_{\frac{1}{2} d_{i} T_{i j}} \cdot \underbrace{\text { number of days per base planning period }}_{t_{b}} \\
& =\frac{1}{2} h_{i} d_{i} T_{i j} t_{b} .
\end{aligned}
$$

To (4) we must add the ordering costs at the retailer. Since the number of orders placed by retailer $i$ to warehouse $j$ is $t_{b} / T_{i j}$, and the cost per order is $o_{i}$, the cost of orders placed by retailer $i$ over the base planning period is $o_{i} t_{b} / T_{i j}$. It follows that for this case

$$
C_{i j}\left(\widehat{T}_{j}, T_{i j}\right)=\frac{o_{i}}{T_{i j}} t_{b}+\frac{1}{2} h_{i} d_{i} T_{i j} t_{b} .
$$

Case 2: $T_{i j} \leq \widehat{T}_{j}$ For this case the inventory holding cost at the warehouse will be nonzero. In general, an inventory vs. time plot for the warehouse can have an arbitrary shape, as shown in Fig. 2, making it difficult to determine the average inventory level. To overcome this problem, Roundy (1985) used the echelon method of computing holding costs (Clark and Scarf 1960), and we shall do the same. Define the system inventory at a retailer $i$ that is served by warehouse $j$ as the inventory at retailer $i$ plus the inventory at the warehouse that is destined for retailer $i$. Then the system inventory has a sawtooth pattern with an order interval of $\widehat{T}_{j}$ (Roundy 1985), as shown in Fig. 3. We can therefore calculate the contribution to the holding costs due to the system inventory using the same method that was used in Case 1 to find the total inventory holding cost at retailer $i$ over the base planning period, except that $\widehat{T}_{j}$ is used in place of $T_{i j}$, and the per-unit holding cost at the warehouse, $\hat{h}_{j}$, is used in place of $h_{i}$, thus obtaining

$$
\frac{1}{2} \hat{h}_{j} d_{i} \widehat{T}_{j} t_{b} .
$$

To (6) we must add the inventory holding cost at the retailer, which is calculated as in Case 1, except that instead of using $h_{i}$, we use the per-unit echelon holding cost at retailer $i, h_{i}-\hat{h}_{j}$, thus obtaining

$$
\frac{1}{2}\left(h_{i}-\hat{h}_{j}\right) d_{i} T_{i j} t_{b}
$$




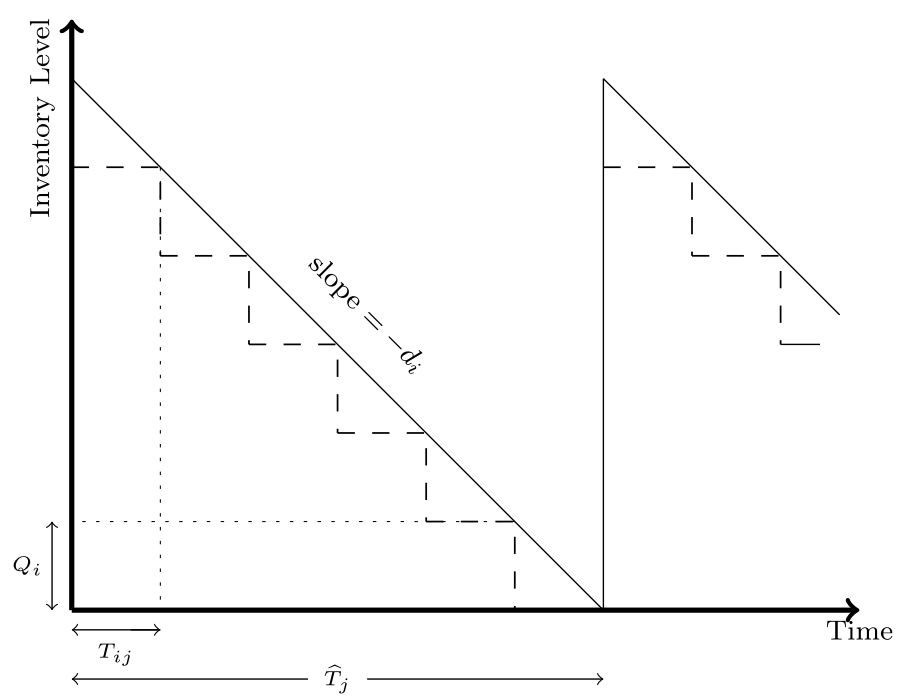

Fig. 3 System inventory for retailer $i$ served by warehouse $j$

We also must include the ordering cost at the retailer, which, by the same calculation used in Case 1 , is $o_{i} t_{b} / T_{i j}$. Adding these costs, we find that

$$
\begin{aligned}
C_{i j}\left(\widehat{T}_{j}, T_{i j}\right) & =\frac{o_{i}}{T_{i j}} t_{b}+\frac{1}{2}\left(h_{i}-\hat{h}_{j}\right) d_{i} T_{i j} t_{b}+\frac{1}{2} \hat{h}_{j} d_{i} \widehat{T}_{j} t_{b} \\
& =\frac{o_{i}}{T_{i j}} t_{b}+\frac{1}{2}\left(h_{i}-\hat{h}_{j}\right) d_{i} T_{i j} t_{b}+\frac{1}{2} \hat{h}_{j} d_{i} \max \left\{\widehat{T}_{j}, T_{i j}\right\} t_{b} .
\end{aligned}
$$

The expressions for $C_{i j}$ in Case 1 (5) and Case 2 (8) can be unified as

$$
C_{i j}\left(\widehat{T}_{j}, T_{i j}\right)=\frac{o_{i}}{T_{i j}} t_{b}+\frac{1}{2}\left(h_{i}-\hat{h}_{j}\right) d_{i} T_{i j} t_{b}+\frac{1}{2} \hat{h}_{j} d_{i} \max \left\{\widehat{T}_{j}, T_{i j}\right\} t_{b}
$$

Substituting (9) into (1), we find that the total inventory and ordering costs for warehouse $j$ and the retailers it serves over the base planning period are

$$
\begin{aligned}
\hat{C}_{j}\left(\widehat{T}_{j},\left\{T_{i j}: i \in \Im_{j}\right\}\right) & =\frac{\hat{o}_{j}}{\widehat{T}_{j}} t_{b}+\sum_{i \in \Im_{j}} C_{i j}\left(\widehat{T}_{j}, T_{i j}\right) \\
& =\frac{\hat{o}_{j}}{\widehat{T}_{j}} t_{b}+\sum_{i \in \Im_{j}}\left(\frac{o_{i}}{T_{i j}} t_{b}+\frac{1}{2}\left(h_{i}-\hat{h}_{j}\right) d_{i} T_{i j} t_{b}+\frac{1}{2} \hat{h}_{j} d_{i} \max \left\{\widehat{T}_{j}, T_{i j}\right\} t_{b}\right) .
\end{aligned}
$$

To specify the open warehouses and the assignments of retailers to warehouses, we introduce decision variables $X_{j}$ and $Y_{i j}$ as follows:

$$
X_{j}= \begin{cases}1 & \text { if a warehouse is opened at candidate location } j \\ 0 & \text { otherwise }\end{cases}
$$




$$
Y_{i j}= \begin{cases}1 & \text { if retailer } i \text { is served by the warehouse at location } j \\ 0 & \text { otherwise. }\end{cases}
$$

Using these variables in (10) and summing over all warehouses $j$, we obtain

$$
\sum_{j \in J} \frac{\hat{o}_{j} t_{b}}{\widehat{T}_{j}} X_{j}+\sum_{j \in J} \sum_{i \in I}\left(\frac{o_{i} t_{b}}{T_{i j}}+\frac{1}{2}\left(h_{i}-\hat{h}_{j}\right) d_{i} t_{b} T_{i j}+\frac{1}{2} \hat{h}_{j} d_{i} t_{b} \max \left\{\widehat{T}_{j}, T_{i j}\right\}\right) Y_{i j} .
$$

To (11), which only takes account of inventory and ordering costs, we must add the location and shipping costs. Let $f_{j}$ be the fixed cost of opening and operating warehouse $j$, let $s_{i j}$ be the per-unit shipping cost from warehouse $j$ to retailer $i$, and let $\hat{s}_{j}$ be the per-unit shipping cost from the plant to warehouse $j$. Adding the costs of opening and operating warehouses and shipping costs to (11), we obtain:

$$
\begin{aligned}
& \sum_{j \in J} \sum_{i \in I}\left(\frac{o_{i} t_{b}}{T_{i j}}+\frac{1}{2}\left(h_{i}-\hat{h}_{j}\right) d_{i} t_{b} T_{i j}+\frac{1}{2} \hat{h}_{j} d_{i} t_{b} \max \left\{\widehat{T}_{j}, T_{i j}\right\}\right) Y_{i j} \\
& \quad+\sum_{j \in J} \frac{\hat{o}_{j} t_{b}}{\widehat{T}_{j}} X_{j}+\sum_{j \in J} f_{j} X_{j}+\sum_{j \in J} \hat{s}_{j}\left(\sum_{i \in I} d_{i} t_{b} Y_{i j}\right)+\sum_{j \in J} \sum_{i \in I} d_{i} t_{b} s_{i j} Y_{i j}
\end{aligned}
$$

where we have used the fact that the demand seen by retailer $i$ over the base planning period is $d_{i} t_{b}$. Rearranging terms in (12), and introducing a weighting factor $\beta_{\text {trn }}$ for transportation costs and a weighting factor $\beta_{\text {inv }}$ for inventory and ordering costs gives

$$
\begin{aligned}
& \sum_{j \in J} \sum_{i \in I}\left(\beta_{\mathrm{inv}} \frac{o_{i} t_{b}}{T_{i j}}+\frac{1}{2} \beta_{\mathrm{inv}}\left(h_{i}-\hat{h}_{j}\right) d_{i} t_{b} T_{i j}+\frac{1}{2} \beta_{\mathrm{inv}} \hat{h}_{j} d_{i} t_{b} \max \left\{\widehat{T}_{j}, T_{i j}\right\}\right) Y_{i j} \\
& \quad+\sum_{j \in J}\left(f_{j}+\beta_{\mathrm{inv}} \frac{\hat{o}_{j} t_{b}}{\widehat{T}_{j}}\right) X_{j}+\sum_{j \in J} \sum_{i \in I} \beta_{\mathrm{trn}} d_{i} t_{b}\left(\hat{s}_{j}+s_{i j}\right) Y_{i j} .
\end{aligned}
$$

For convenience we define

$$
\begin{aligned}
k_{i} & =\beta_{\text {inv }} o_{i} t_{b} \\
\hat{k}_{j} & =\beta_{\text {inv }} \hat{o}_{j} t_{b} \\
b_{i j} & =\beta_{\text {trn }}\left(\hat{s}_{j}+s_{i j}\right) d_{i} t_{b} \\
c_{i j} & =\frac{1}{2} \beta_{\text {inv }}\left(h_{i}-\hat{h}_{j}\right) d_{i} t_{b} \\
e_{i j} & =\frac{1}{2} \beta_{\text {inv }} \hat{h}_{j} d_{i} t_{b} .
\end{aligned}
$$

Then the total inventory, ordering, location, and shipping costs can be expressed as

$$
\sum_{j \in J}\left(f_{j}+\frac{\hat{k}_{j}}{\widehat{T}_{j}}\right) X_{j}+\sum_{j \in J} \sum_{i \in I}\left(\frac{k_{i}}{T_{i j}}+b_{i j}+c_{i j} T_{i j}+e_{i j} \max \left\{\widehat{T}_{j}, T_{i j}\right\}\right) Y_{i j} .
$$

We can now formulate the Multi-echelon Joint Inventory-Location (MJIL) problem as 


$$
\begin{aligned}
& \min _{X, Y, \widehat{T}, T} \sum_{j \in J}\left(f_{j}+\frac{\hat{k}_{j}}{\widehat{T}_{j}}\right) X_{j}+\sum_{j \in J} \sum_{i \in I}\left(\frac{k_{i}}{T_{i j}}+b_{i j}+c_{i j} T_{i j}+e_{i j} \max \left\{\widehat{T}_{j}, T_{i j}\right\}\right) Y_{i j} \\
& \text { s.t. } \quad \sum_{j \in J} Y_{i j}=1 \quad \forall i \in I \\
& Y_{i j} \leq X_{j} \quad \forall i \in I, \forall j \in J \\
& Y_{i j} \in\{0,1\} \quad \forall i \in I, \forall j \in J \\
& X_{j} \in\{0,1\} \quad \forall j \in J \\
& \widehat{T}_{j} / T_{i j}=2^{N_{i j}} \quad \forall i \in I, \forall j \in J \\
& N_{i j} \in \mathbb{Z} \quad \forall i \in I, \forall j \in J \\
& \widehat{T}_{j}>0 \quad \forall j \in J \\
& T_{i j}>0 \quad \forall i \in I, \forall j \in J .
\end{aligned}
$$

Constraints (16) require that each retailer be assigned to exactly one warehouse. Constraints (17) prevent retailers from being assigned to warehouses that are closed. Constraints (18) and (19) require that $Y_{i j}$ and $X_{j}$ be binary. Finally, Constraints (20) through (23) require a power-of-two inventory policy at the retailers and the warehouses.

Next we reformulate (15)-(23) as a nonlinear uncapacitated facility location problem by first optimizing over $T$ and $\widehat{T}$ for any given $X$ and $Y$ satisfying (16)-(19), and then optimizing over $X$ and $Y$. We obtain:

$$
\begin{aligned}
& \min _{X, Y} \sum_{j \in J}\left(f_{j} X_{j}+\sum_{i \in I} b_{i j} Y_{i j}+Z_{j}^{*}\left(\Im_{j}, X_{j}\right)\right) \\
& \text { s.t. } \quad \sum_{j \in J} Y_{i j}=1 \quad \forall i \in I, \forall j \in J \\
& Y_{i j} \leq X_{j} \quad \forall i \in I, \forall j \in J \\
& Y_{i j} \in\{0,1\} \quad \forall i \in I, \forall j \in J \\
& X_{j} \in\{0,1\} \quad \forall j \in J
\end{aligned}
$$

where

$$
\mathfrak{\Im}_{j}=\left\{i \in I \mid Y_{i j}=1\right\}
$$

and where

$$
Z_{j}^{*}\left(\Im_{j}, X_{j}\right)=\min _{\widehat{T}_{j}, T_{i j}}\left\{\begin{array}{l}
\frac{\hat{k}_{j}}{\widehat{T}_{j}} X_{j}+\sum_{i \in \Im_{j}}\left(\frac{k_{i}}{T_{i j}}+c_{i j} T_{i j}+e_{i j} \max \left(T_{i j}, \widehat{T}_{j}\right)\right) \\
\text { s.t. } \widehat{T}_{j} / T_{i j}=2^{N_{i j}} \text { where } N_{i j} \in \mathbb{Z}, T_{i j}>0, \text { and } \widehat{T}_{j}>0
\end{array}\right\} .
$$

\section{Solving the MJIL problem using Lagrangian relaxation}

The MJIL problem is a generalization of the uncapacitated fixed-charge location problem, which is known to be NP-hard (Daskin 1995); it follows that the MJIL problem is also NPhard. A number of algorithms have shown success in solving such problems, including Lagrangian relaxation (Chen and Chu 2003; Eskigun et al. 2005; Fisher 1981, 1985; Jayaraman 
and Pirkul 2001; Min et al. 2005; Pirkul and Jayaraman 1998; Putz 2007), column generation (Romeijn et al. 2007), and various heuristic methods such as genetic algorithms (Chan et al. 2005), simulated annealing (Jayaraman and Ross 2003), and tabu search (Shiguemoto and Armentano 2010); here we develop a Lagrangian relaxation approach to solving the MJIL problem.

The first step in developing this approach is to consider the Lagrangian dual problem obtained by relaxing Constraints (25):

$$
\begin{aligned}
& \max _{\lambda \geq 0} \min _{X, Y} \quad \sum_{j \in J}\left(f_{j} X_{j}+\sum_{i \in I} b_{i j} Y_{i j}+Z_{j}^{*}\left(\Im_{j}, X_{j}\right)\right)+\sum_{i \in I} \lambda_{i}\left(1-\sum_{j \in J} Y_{i j}\right) \\
& \quad=\max _{\lambda \geq 0} \sum_{j \in J} \min _{X_{j},\left\{Y_{i j}: i \in I\right\}}\left(f_{j} X_{j}+\sum_{i \in I}\left(b_{i j}-\lambda_{i}\right) Y_{i j}+Z_{j}^{*}\left(\Im_{j}, X_{j}\right)\right)+\sum_{i \in I} \lambda_{i} \\
& \text { s.t. } \quad Y_{i j} \leq X_{j} \quad \forall i \in I, \forall j \in J \\
& \quad Y_{i j} \in\{0,1\} \quad \forall i \in I, \forall j \in J \\
& \quad X_{j} \in\{0,1\} \quad \forall j \in J \\
& =\max _{\lambda \geq 0} \sum_{j \in J} S_{j}^{*}(\lambda)+\sum_{i \in I} \lambda_{i}
\end{aligned}
$$

where

$$
S_{j}^{*}(\lambda)=\min _{X_{j},\left\{Y_{i j}: i \in I\right\}}\left\{\begin{array}{l}
f_{j} X_{j}+\sum_{i \in I}\left(b_{i j}-\lambda_{i}\right) Y_{i j}+Z_{j}^{*}\left(\Im_{j}, X_{j}\right) \\
\text { s.t. } Y_{i j} \leq X_{j} \forall i \in I, X_{j} \in\{0,1\}, \text { and } Y_{i j} \in\{0,1\} \forall i \in I
\end{array}\right\} .
$$

Thus we see that the Lagrangian relaxation problem decomposes into $|J|$ subproblems, one for each warehouse $j \in J$. The subproblem corresponding to warehouse $j$ is denoted $S_{j}(\lambda)$, and the value of the objective function of this subproblem at optimality is denoted $S_{j}^{*}(\lambda)$. The strategy we will use to solve the subproblems $S_{j}(\lambda)$ is to alternate between optimizing over $X_{j}$ and $\left\{Y_{i j}: i \in I\right\}$ for fixed $\widehat{T}_{j}$ and $\left\{T_{i j}: i \in I\right\}$, and optimizing over $\widehat{T}_{j}$ and $\left\{T_{i j}: i \in \mathfrak{\Im}_{j}\right\}$ for fixed $X_{j}$ and $\left\{Y_{i j}: i \in I\right\}$ until a convergence criterion is satisfied. For a fixed assignment of retailers to warehouses, that is, for fixed $X_{j}$ and $Y_{i j}, Z_{j}^{*}\left(\Im_{j}, X_{j}\right)$ is the optimal value of a power-of-two multi-echelon inventory problem for warehouse $j$, and is thus an instance of the problem considered by Roundy (1985). Roundy developed an algorithm to solve this problem which relaxes the power-of-two constraints; the solution to this relaxed problem, when appropriately rounded, gives a nearly optimal solution to the problem with the power-to-two constraints in place. More specifically, Roundy showed that for one warehouse serving multiple retailers, this approach to generating a power-of-two inventory policy is at least $98 \%$ effective (Roundy 1985), meaning that if $Z_{j}^{\prime}\left(\mathfrak{s}_{j}, X_{j}\right)$ is the contribution to the inventory costs, on average, of a single warehouse $j$ and the retailers it serves for the power-of-two inventory policy found using the above algorithm, and if $\tilde{Z}_{j}\left(\mathfrak{\Im}_{j}, X_{j}\right)$ is the infimum of the average cost over all policies at warehouse $j$, then

$$
100 \times \frac{\tilde{Z}_{j}\left(\mathfrak{\Im}_{j}, X_{j}\right)}{Z_{j}^{\prime}\left(\mathfrak{\Im}_{j}, X_{j}\right)} \geq 98
$$


However, the inventory term in our objective function (24) has the form $\sum_{j \in J} Z_{j}\left(\Im_{j}, X_{j}\right)$, so we need to bound

$$
\frac{\sum_{j \in J} \tilde{Z}_{j}\left(\Im_{j}, X_{j}\right)}{\sum_{j \in J} Z_{j}^{\prime}\left(\Im_{j}, X_{j}\right)} .
$$

Such a bound can be obtained as follows. From (34) it follows that

$$
100 \times \tilde{Z}_{j}\left(\mathfrak{s}_{j}, X_{j}\right) \geq 98 \times Z_{j}^{\prime}\left(\mathfrak{\Im}_{j}, X_{j}\right) .
$$

Hence, summing over $j$, we obtain

$$
100 \times \sum_{j \in J} \tilde{Z}_{j}\left(\Im_{j}, X_{j}\right) \geq 98 \times \sum_{j \in J} Z_{j}^{\prime}\left(\Im_{j}, X_{j}\right)
$$

or

$$
100 \times \frac{\sum_{j \in J} \tilde{Z}_{j}\left(\Im_{j}, X_{j}\right)}{\sum_{j \in J} Z_{j}^{\prime}\left(\Im_{j}, X_{j}\right)} \geq 98 .
$$

If follows that the overall power-of-two inventory policy considering all warehouses $j$ is 98\% efficient for a fixed assignment of retailers to warehouses. As Roundy's algorithm provides a means of obtaining a near-optimal power-of-two inventory policy for fixed $X_{j}$ and $\left\{Y_{i j}: i \in I\right\}$, we use this method to obtain $\widehat{T}_{j}$ and $\left\{T_{i j}: i \in \Im_{j}\right\}$ for fixed $X_{j}$ and $\left\{Y_{i j}\right.$ : $i \in I\}$.

We now turn to the optimization over $X_{j}$ and $\left\{Y_{i j}: i \in I\right\}$ for fixed $\widehat{T}_{j}$ and $\left\{T_{i j}: i \in I\right\}$ in subproblem $S_{j}(\lambda)$ (33). For fixed $\widehat{T}_{j}$ and $\left\{T_{i j}: i \in I\right\}$, the coefficients of $X_{j}$ and $\left\{Y_{i j}: i \in I\right\}$ in subproblem $S_{j}(\lambda)$ become constant, so that the optimal values of $X_{j}$ and $\left\{Y_{i j}: i \in I\right\}$ can be found by the following algorithm:

1. If the coefficient of $Y_{i j}$ is positive and $Y_{i j}$ is 1 , set $Y_{i j}=0$.

2. Fixing $\left\{Y_{i j}: i \in I\right\}$, and keeping $\widehat{T}_{j}$ and $\left\{T_{i j}: i \in I\right\}$ fixed, set $X_{j}=0$ or 1 according to whichever value minimizes the objective function (33). If a zero value results for $X_{j}$, go back and set $Y_{i j}=0$ for $i \in I$.

Solving the subproblems $S_{j}(\lambda)$ (33) and substituting the result back into the objective function (32) gives a lower bound on the objective function value for the MJIL problem, provided the subproblems $S_{j}(\lambda)$ are solved to optimality. If any of the subproblems are not solved to optimality, then the "lower bound" on the optimal objective function value of the original problem that results from a particular value of $\lambda$ may not be a lower bound at all. Since in our case the subproblems $S_{j}(\lambda)$ are nonlinear and nonconvex in the decision variables, they are difficult to solve to optimality. Nevertheless, if the algorithm that carries out the minimizations indicated by the subproblems $S_{j}(\lambda)$ is sufficiently effective, the overall process may still function as a useful heuristic for obtaining a good solution to the original problem, but with no guarantee that the "lower bound" is a true lower bound.

An upper bound on the MJIL problem, which is useful for the optimization over the $\lambda_{i}$ 's, is provided by any feasible solution. Our approach to constructing a feasible solution uses the solution of (32) as a starting point. Retailers $i$ that have not been assigned to any warehouse are assigned to the warehouse $j^{\prime}$ having the smallest coefficient of $Y_{i j^{\prime}}$ in (15) over all the warehouses that are open, while retailers $i$ that have been assigned to multiple warehouses $j$ belonging to a set $J^{\prime}$ are assigned to the warehouse $j^{\prime} \in J^{\prime}$ having the smallest coefficient of $Y_{i j^{\prime}}$ in (15). This procedure produces a solution $(\tilde{X}, \tilde{Y})$ that satisfies (25)-(28). Further details are provided in procedure CalculateFeasibleSolution (Algorithm 1). 


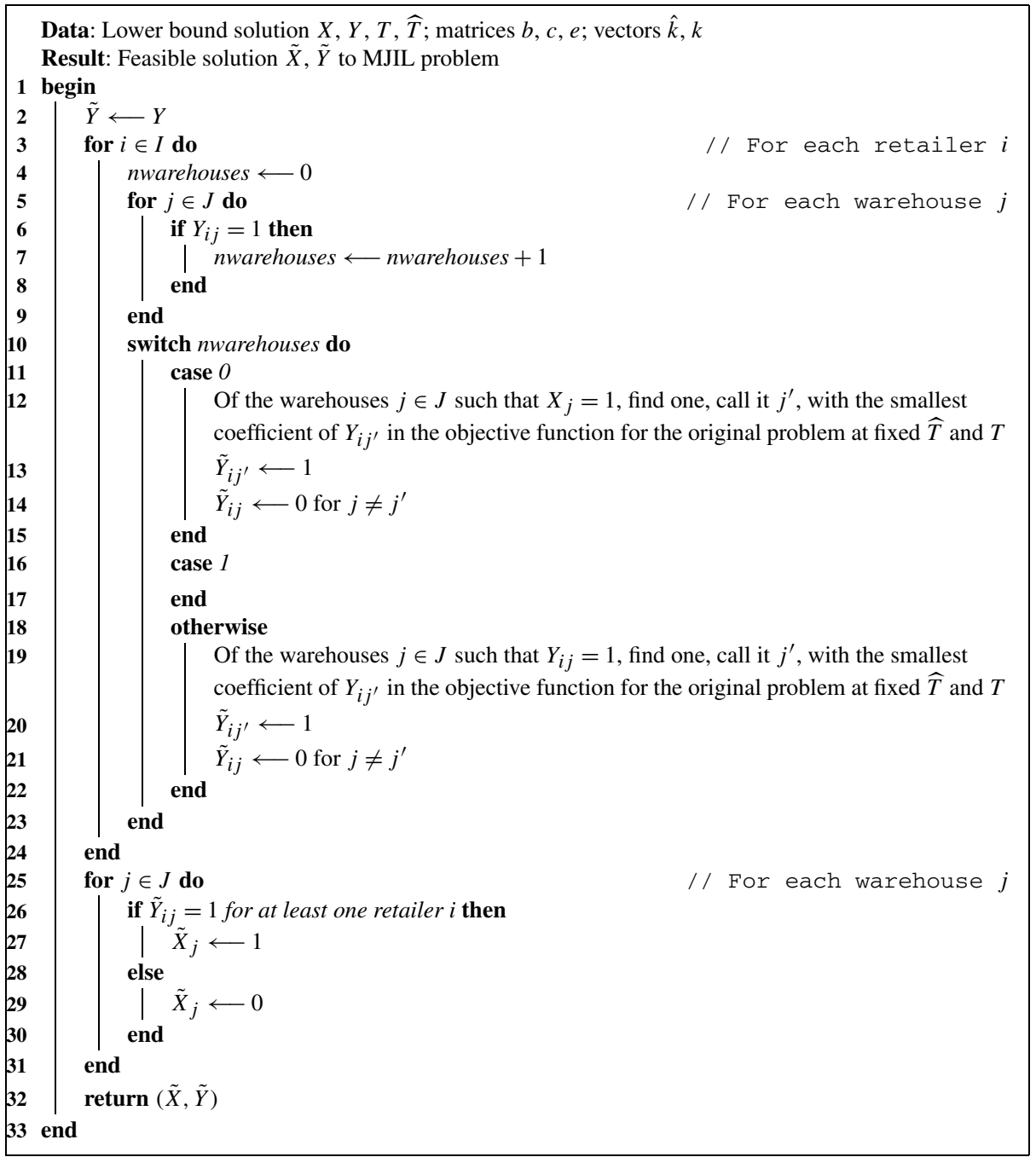

Algorithm 1: CalculateFeasibleSolution

The overall Lagrangian relaxation procedure consists of an outer loop and inner loop. The outer loop maximizes over the $\lambda_{i}$ 's using a subgradient optimization procedure (see Putz 2007), while the inner loop minimizes over $X, Y, T$, and $\widehat{T}$. The subgradient optimization uses an "agility" parameter $\pi$, which is initially set to 2 , and is reduced by dividing by an "agility reduction factor" (denoted $\alpha$ ) every time $N_{\pi}$ iterations are performed without improvement in the solution. We experimented with several different values of $\alpha$ and $N_{\pi}$, and chose values for these parameters that gave the best results; in particular, we set $\alpha=1.2$ and $N_{\pi}=100$. Since the lower bound obtained is not necessarily a true lower bound, the algorithm includes a test to ensure that the best upper bound at a given point in the optimization is greater than the best lower bound to this point; if not, the best lower bound solution is discarded. Details of the Lagrangian relaxation are provided in procedure SolveMJIL (Algorithm 2). 


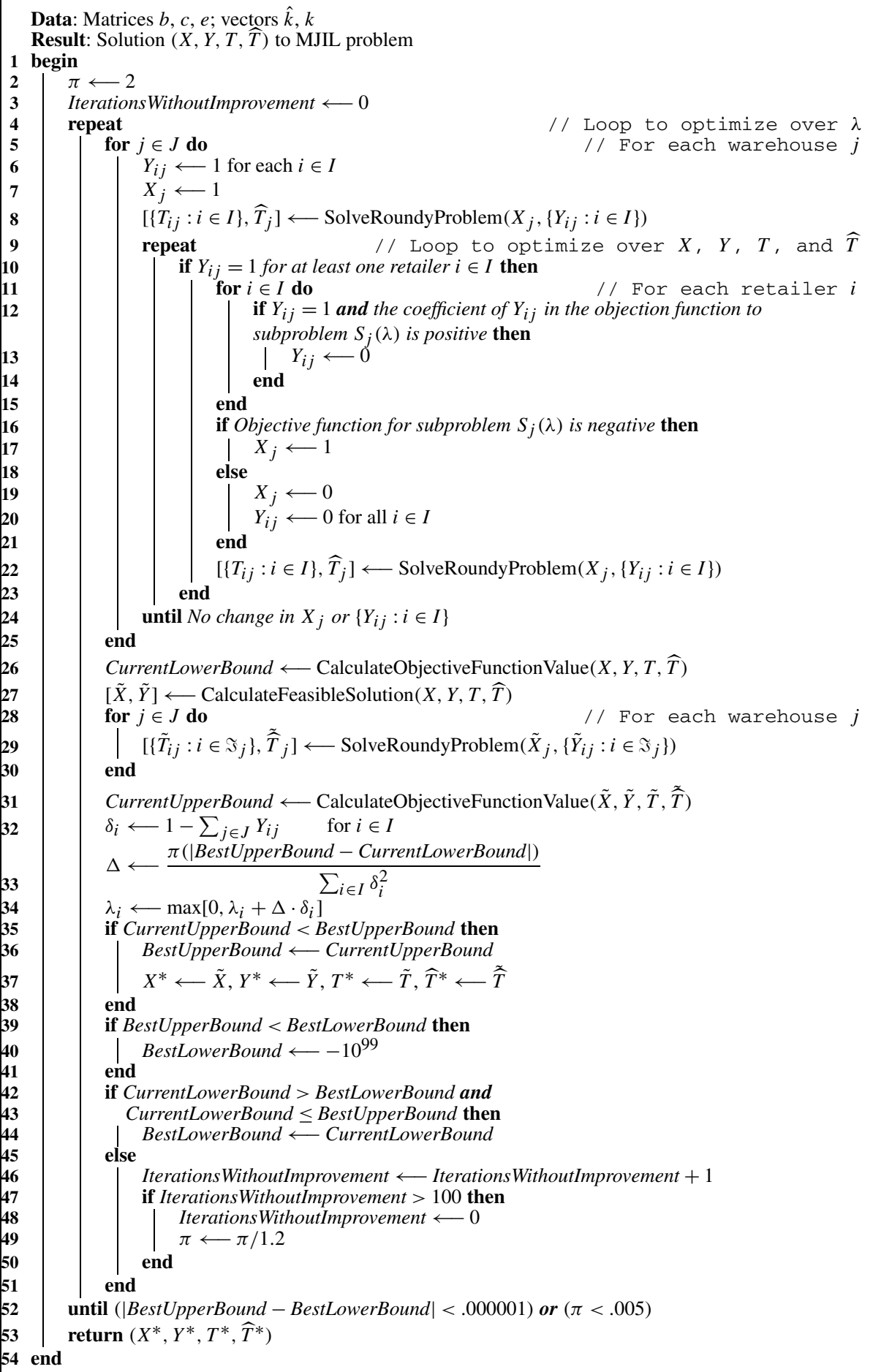




\section{Computational study}

We tested our algorithm on the following data sets, derived from Daskin (1995):

- a 49-node data set (48 continental US state capitals plus Washington, DC; 1990 census data);

- an 88-node data set (49-node dataset plus the 50 largest US cities minus duplicates; 1990 census data); and

- a 150-node data set (150 largest US cities; 1990 census data).

The Lagrangian relaxation algorithm described in Sect. 4 was implemented in C\#, and computer experiments were run on a $2.8 \mathrm{GHz}$ dual core processor with $8 \mathrm{~GB}$ of RAM.

In order to determine the value of integrating location and inventory decisions, we generated 36 scenarios for each data set by varying the values of the transportation cost weighting factor $\beta_{\mathrm{trn}}$ and the inventory cost weighting factor $\beta_{\mathrm{inv}}$ such that

$$
\beta_{\text {trn }} \in\{0.001,0.01,0.1,1,10,100\} \quad \text { and } \quad \beta_{\text {inv }} \in\{0.001,0.01,0.1,1,10,100\} .
$$

These values allow the benefits of integration to be evaluated for different relative weightings of transportation costs and inventory costs.

We computed the Value of Integration (VOI), which measures the benefit obtained from integrating location, transportation, and inventory decisions, as follows:

$$
\text { Value of Integration }=100 \times \frac{(\text { Best UB for Sequential Opt. })-(\text { Best UB for Joint Opt. })}{\text { Best UB for Joint Opt. }} .
$$

In the above expression, "Best UB for Joint Opt." refers to the best upper bound obtained by integrating location, transportation, and inventory decisions, while "Best UB for Sequential Opt." refers to the best upper bound obtained by first solving a transportation-location problem to obtain an assignment of retailers to warehouses, and then solving an inventory problem at each warehouse based on these assignments.

Table 1 provides results for a small problem with 11 retailers and 5 warehouses that is derived from the 49-city data set for which the optimal solution can be calculated by exhaustive search; this table shows that the algorithm found an optimal solution in 36 out of 36 scenarios. On this problem, there was only one positive VOI, with all other VOI being zero, indicating that over much of the $\left(\beta_{\text {trn }}, \beta_{\text {inv }}\right)$ parameter space, there is little benefit to integration. The positive VOI occurred at $\left(\beta_{\text {trn }}, \beta_{\text {inv }}\right)=(0.1,100)$, indicating a clear benefit to integration in this region of the parameter space.

Tables 2-4 provide results for the 49-city, 88-city, and 150-city data sets, in which every city represents a retailer location as well as a candidate warehouse location. Again, most of the VOI were zero, indicating that there is little benefit to integration over much of the $\left(\beta_{\text {trn }}, \beta_{\text {inv }}\right)$ parameter space. However, there were some positive VOI: for the 49-city data set, positive VOI occurred at $\left(\beta_{\text {trn }}, \beta_{\text {inv }}\right)=(0.1,10),(0.1,100),(1,10),(1,100)$; for the 88city data set, positive VOI occurred at $\left(\beta_{\text {trn }}, \beta_{\text {inv }}\right)=(0.01,10),(0.01,100),(.1,1),(.1,10)$, $(.1,100)$; and for the 150 -city data set, positive VOI occurred at $\left(\beta_{\text {trn }}, \beta_{\text {inv }}\right)=(0.1,100)$, $(1,100)$. These positive VOI reveal a clear benefit to integration over the corresponding regions of the parameter space.

Tables 1-4 also reveal that in some cases the VOI was negative, indicating that sequential (non-integrated) optimization gave a better solution than joint (integrated) optimization. One of the reasons that this can occur is that the joint optimization approach uses Lagrangian relaxation to solve a combined transportation-location-inventory problem. In this case the 
Table 1 Results for 11 retailers and 5 candidate warehouse locations chosen from the 49-city data set (retailers in cities $\{1-11\}$, candidate warehouse locations in cities $\{4,11,24,35,47\}$ ), for $\beta_{\operatorname{trn}} \in$ $\{0.001,0.01,0.1,1,10,100\}, \beta_{\text {inv }} \in\{0.001,0.01,0.1,1,10,100\}$. The plant is at acation near Atlanta, Georgia, at longitude 84 and latitude 33. Per-unit shipping costs between the plant and warehouses were obtained by multiplying the great-circle distances between the locations by .04 , and per unit shipping costs between the warehouses and the retailers were obtained by multiplying the great-circle distances between the locations by .05. Demand at a retailer was obtained by multiplying the 5 th column in the 49-city dataset by .0001 . The fixed order cost at a warehouse was obtained by multiplying the 6th column in the 49-city dataset by 2.5 . For each retailer, the unit inventory cost and the fixed order cost were respectively $\$ 4.30$ and $\$ 2.10$, while for each warehouse, the unit inventory cost and the fixed order cost were respectively $\$ 2.60$ and $\$ 1.80$. The base planning period was taken as 365 days. DCs $=$ Number of open warehouses, Gap $=$ BestUpperBound - BestLowerBound, VOI = Value of Integration

\begin{tabular}{|c|c|c|c|c|c|c|c|}
\hline No. & $\beta_{\mathrm{trn}}$ & $\beta_{\text {inv }}$ & DCs & $\begin{array}{l}\text { Time } \\
\text { (sec.) }\end{array}$ & $\begin{array}{l}\text { Obtained } \\
\text { value }\end{array}$ & Gap & VOI \\
\hline
\end{tabular}

\begin{tabular}{|c|c|c|c|c|c|c|c|c|}
\hline 1 & 0.001 & 0.001 & 1 & 0.031 & 216368.057 & $2.910 \mathrm{E}-11$ & 0.0000 & 216368.057 \\
\hline 2 & 0.001 & 0.010 & 1 & 0.016 & 217119.219 & $2.910 \mathrm{E}-11$ & 0.0000 & 217119.219 \\
\hline 3 & 0.001 & 0.100 & 1 & 0.016 & 224630.836 & $8.731 \mathrm{E}-11$ & 0.0000 & 224630.836 \\
\hline 4 & 0.001 & 1 & 1 & 0.016 & 299747.009 & $0.000 \mathrm{E}+00$ & 0.0000 & 299747.009 \\
\hline 5 & 0.001 & 10 & 1 & 0.031 & 1050908.738 & $0.000 \mathrm{E}+00$ & 0.0000 & 1050908.738 \\
\hline 6 & 0.001 & 100 & 1 & 0.078 & 8562526.023 & $1.863 \mathrm{E}-09$ & 0.0000 & 8562526.023 \\
\hline 7 & 0.010 & 0.001 & 1 & 0.062 & 538565.345 & $0.000 \mathrm{E}+00$ & 0.0000 & 538565.345 \\
\hline 8 & 0.010 & 0.010 & 1 & 0.062 & 539316.507 & $0.000 \mathrm{E}+00$ & 0.0000 & 539316.507 \\
\hline 9 & 0.010 & 0.100 & 1 & 0.640 & 546828.124 & $0.000 \mathrm{E}+00$ & 0.0000 & 546828.124 \\
\hline 10 & 0.010 & 1 & 1 & 0.047 & 621944.297 & $0.000 \mathrm{E}+00$ & 0.0000 & 621944.297 \\
\hline 11 & 0.010 & 10 & 1 & 0.078 & 1373106.025 & $2.328 \mathrm{E}-10$ & 0.0000 & 1373106.025 \\
\hline 12 & 0.010 & 100 & 1 & 0.031 & 8884723.311 & $1.863 \mathrm{E}-09$ & 0.0000 & 8884723.311 \\
\hline 13 & 0.100 & 0.001 & 2 & 0.000 & 3333735.921 & $0.000 \mathrm{E}+00$ & 0.0000 & 3333735.921 \\
\hline 14 & 0.100 & 0.010 & 2 & 0.031 & 3334522.496 & $0.000 \mathrm{E}+00$ & 0.0000 & 3334522.496 \\
\hline 15 & 0.100 & 0.100 & 2 & 0.031 & 3342388.244 & $0.000 \mathrm{E}+00$ & 0.0000 & 3342388.244 \\
\hline 16 & 0.100 & 1 & 2 & 0.016 & 3421045.732 & $0.000 \mathrm{E}+00$ & 0.0000 & 3421045.732 \\
\hline 17 & 0.100 & 10 & 2 & 0.031 & 4207620.605 & $0.000 \mathrm{E}+00$ & 0.0000 & 4207620.605 \\
\hline 18 & 0.100 & 100 & 1 & 0.016 & 11904627.672 & $1.863 \mathrm{E}-09$ & 1.4174 & 11904627.672 \\
\hline 19 & 1 & 0.001 & 3 & 0.000 & 27890684.715 & $0.000 \mathrm{E}+00$ & 0.0000 & 27890684.715 \\
\hline 20 & 1 & 0.010 & 3 & 0.047 & 27891499.912 & $3.725 \mathrm{E}-09$ & 0.0000 & 27891499.912 \\
\hline 21 & 1 & 0.100 & 3 & 0.016 & 27899651.890 & $0.000 \mathrm{E}+00$ & 0.0000 & 27899651.890 \\
\hline 22 & 1 & 1 & 3 & 0.000 & 27981171.665 & $0.000 \mathrm{E}+00$ & 0.0000 & 27981171.665 \\
\hline 23 & 1 & 10 & 3 & 0.016 & 28796369.420 & $0.000 \mathrm{E}+00$ & 0.0000 & 28796369.420 \\
\hline 24 & 1 & 100 & 3 & 0.000 & 36948346.963 & $0.000 \mathrm{E}+00$ & 0.0000 & 36948346.963 \\
\hline 25 & 10 & 0.001 & 4 & 0.000 & 271799222.557 & $0.000 \mathrm{E}+00$ & 0.0000 & 271799222.557 \\
\hline 26 & 10 & 0.010 & 4 & 0.000 & 271800052.834 & $0.000 \mathrm{E}+00$ & 0.0000 & 271800052.834 \\
\hline 27 & 10 & 0.100 & 4 & 0.000 & 271808355.606 & $0.000 \mathrm{E}+00$ & 0.0000 & 271808355.606 \\
\hline 28 & 10 & 1 & 4 & 0.000 & 271891383.318 & $0.000 \mathrm{E}+00$ & 0.0000 & 271891383.318 \\
\hline 29 & 10 & 10 & 4 & 0.000 & 272721660.437 & $0.000 \mathrm{E}+00$ & 0.0000 & 272721660.437 \\
\hline 30 & 10 & 100 & 4 & 0.000 & 281024431.628 & $0.000 \mathrm{E}+00$ & 0.0000 & 281024431.628 \\
\hline 31 & 100 & 0.001 & 4 & 0.000 & 2710237895.296 & $0.000 \mathrm{E}+00$ & 0.0000 & 2710237895.296 \\
\hline 32 & 100 & 0.010 & 4 & 0.000 & 2710238725.573 & $0.000 \mathrm{E}+00$ & 0.0000 & 2710238725.573 \\
\hline 33 & 100 & 0.100 & 4 & 0.000 & 2710247028.344 & $0.000 \mathrm{E}+00$ & 0.0000 & 2710247028.344 \\
\hline 34 & 100 & 1 & 4 & 0.000 & 2710330056.056 & $0.000 \mathrm{E}+00$ & 0.0000 & 2710330056.056 \\
\hline 35 & 100 & 10 & 4 & 0.000 & 2711160333.175 & $0.000 \mathrm{E}+00$ & 0.0000 & 2711160333.175 \\
\hline 36 & 100 & 100 & 4 & 0.016 & 2719463104.366 & $0.000 \mathrm{E}+00$ & 0.0000 & 2719463104.366 \\
\hline
\end{tabular}


Table 2 Results for 49 retailers and 49 candidate warehouse locations chosen from the 49-city data set (retailers in cities $\{1-49\}$, candidate warehouse locations in cities $\{1-49\}$ ), for $\beta_{\operatorname{trn}} \in$ $\{0.001,0.01,0.1,1,10,100\}, \beta_{\text {inv }} \in\{0.001,0.01,0.1,1,10,100\}$. The plant is at a location near Atlanta, Georgia, at longitude 84 and latitude 33. Per-unit shipping costs between the plant and warehouses were obtained by multiplying the great-circle distances between the locations by .04 , and per unit shipping costs between the warehouses and the retailers were obtained by multiplying the great-circle distances between the locations by .05 . Demand at a retailer was obtained by multiplying the 5 th column in the 49-city dataset by .0001 . The fixed order cost at a warehouse was obtained by multiplying the 6th column in the 49-city dataset by 2.5 . For each retailer, the unit inventory cost and the fixed order cost were respectively $\$ 4.30$ and $\$ 2.10$, while for each warehouse, the unit inventory cost and the fixed order cost were respectively $\$ 2.60$ and $\$ 1.80$. The base planning period was taken as 365 days. DCs $=$ Number of open warehouses, Gap $=$ BestUpperBound - BestLowerBound, VOI = Value of Integration

\begin{tabular}{|c|c|c|c|c|c|c|c|}
\hline No. & $\beta_{\text {trn }}$ & $\beta_{\text {inv }}$ & DCs & $\begin{array}{l}\text { Time } \\
\text { (sec.) }\end{array}$ & $\begin{array}{l}\text { Obtained } \\
\text { value }\end{array}$ & Gap & VOI \\
\hline 1 & 0.001 & 0.001 & 1 & 0.078 & 224371.213 & $2.910 \mathrm{E}-10$ & 0.0000 \\
\hline 2 & 0.001 & 0.010 & 1 & 0.078 & 227205.891 & $2.328 \mathrm{E}-10$ & 0.0000 \\
\hline 3 & 0.001 & 0.100 & 1 & 0.094 & 255552.669 & $2.619 \mathrm{E}-10$ & 0.0000 \\
\hline 4 & 0.001 & 1 & 1 & 0.078 & 539020.450 & $2.328 \mathrm{E}-10$ & 0.0000 \\
\hline 5 & 0.001 & 10 & 1 & 0.484 & 3373698.259 & $1.397 \mathrm{E}-09$ & 0.0000 \\
\hline 6 & 0.001 & 100 & 1 & 1.420 & 31720476.352 & $0.000 \mathrm{E}+00$ & 0.0000 \\
\hline 7 & 0.010 & 0.001 & 1 & 1.420 & 1142877.451 & $0.000 \mathrm{E}+00$ & 0.0000 \\
\hline 8 & 0.010 & 0.010 & 1 & 0.936 & 1145712.129 & $0.000 \mathrm{E}+00$ & 0.0000 \\
\hline 9 & 0.010 & 0.100 & 1 & 0.281 & 1174058.907 & $0.000 \mathrm{E}+00$ & 0.0000 \\
\hline 10 & 0.010 & 1 & 1 & 0.764 & 1457526.688 & $0.000 \mathrm{E}+00$ & 0.0000 \\
\hline 11 & 0.010 & 10 & 1 & 1.498 & 4292204.498 & $0.000 \mathrm{E}+00$ & 0.0000 \\
\hline 12 & 0.010 & 100 & 1 & 1.778 & 32638982.591 & $0.000 \mathrm{E}+00$ & 0.0000 \\
\hline 13 & 0.100 & 0.001 & 4 & 0.281 & 8699402.387 & $0.000 \mathrm{E}+00$ & 0.0000 \\
\hline 14 & 0.100 & 0.010 & 4 & 0.218 & 8702356.867 & $0.000 \mathrm{E}+00$ & 0.0000 \\
\hline 15 & 0.100 & 0.100 & 4 & 1.030 & 8731901.667 & $0.000 \mathrm{E}+00$ & 0.0000 \\
\hline 16 & 0.100 & 1 & 4 & 0.437 & 9027349.664 & $0.000 \mathrm{E}+00$ & 0.0000 \\
\hline 17 & 0.100 & 10 & 4 & 0.312 & 11981282.406 & $1.863 \mathrm{E}-09$ & 0.0046 \\
\hline 18 & 0.100 & 100 & 3 & 6.131 & 41456373.509 & $0.000 \mathrm{E}+00$ & 0.1695 \\
\hline 19 & 1 & 0.001 & 12 & 4.384 & 77858549.481 & $2.980 \mathrm{E}-08$ & 0.0000 \\
\hline 20 & 1 & 0.010 & 12 & 4.586 & 77861692.825 & $0.000 \mathrm{E}+00$ & 0.0000 \\
\hline 21 & 1 & 0.100 & 12 & 2.902 & 77893126.262 & $0.000 \mathrm{E}+00$ & 0.0000 \\
\hline 22 & 1 & 1 & 12 & 1.186 & 78207460.629 & $2.980 \mathrm{E}-08$ & 0.0000 \\
\hline 23 & 1 & 10 & 11 & 2.434 & 81336317.615 & $1.490 \mathrm{E}-08$ & 0.0178 \\
\hline 24 & 1 & 100 & 8 & 0.952 & 112593155.815 & $0.000 \mathrm{E}+00$ & 0.1697 \\
\hline 25 & 10 & 0.001 & 20 & 1.326 & 756654372.395 & $1.192 \mathrm{E}-07$ & 0.0000 \\
\hline 26 & 10 & 0.010 & 20 & 1.357 & 756657660.527 & $1.192 \mathrm{E}-07$ & 0.0000 \\
\hline 27 & 10 & 0.100 & 20 & 0.796 & 756690541.847 & $1.192 \mathrm{E}-07$ & 0.0000 \\
\hline 28 & 10 & 1 & 20 & 0.406 & 757019355.053 & $0.000 \mathrm{E}+00$ & 0.0000 \\
\hline 29 & 10 & 10 & 19 & 1.466 & 760337964.728 & $0.000 \mathrm{E}+00$ & -0.0040 \\
\hline 30 & 10 & 100 & 15 & 0.702 & 793237736.173 & $2.384 \mathrm{E}-07$ & -0.0062 \\
\hline 31 & 100 & 0.001 & 25 & 0.359 & 7528209253.929 & $9.537 \mathrm{E}-07$ & 0.0000 \\
\hline 32 & 100 & 0.010 & 25 & 4.306 & 7528212631.264 & $0.000 \mathrm{E}+00$ & 0.0000 \\
\hline 33 & 100 & 0.100 & 25 & 2.465 & 7528246404.605 & $0.000 \mathrm{E}+00$ & 0.0000 \\
\hline 34 & 100 & 1 & 25 & 0.359 & 7528584138.016 & $9.537 \mathrm{E}-07$ & 0.0000 \\
\hline 35 & 100 & 10 & 25 & 0.764 & 7531961472.129 & $0.000 \mathrm{E}+00$ & 0.0000 \\
\hline 36 & 100 & 100 & 25 & 18.018 & 7565734813.262 & $3.815 \mathrm{E}-06$ & 0.0000 \\
\hline
\end{tabular}


Table 3 Results for 88 retailers and 88 candidate warehouse locations chosen from the 88-city data set (retailers in cities $\{1-88\}$, candidate warehouse locations in cities $\{1-88\}$ ), for $\beta_{\operatorname{trn}} \in$ $\{0.001,0.01,0.1,1,10,100\}, \beta_{\text {inv }} \in\{0.001,0.01,0.1,1,10,100\}$. The plant is a location near Atlanta, Georgia, at longitude 84 and latitude 33. Per-unit shipping costs between the plant and warehouses were obtained by multiplying the great-circle distances between the locations by .04 , and per unit shipping costs between the warehouses and the retailers were obtained by multiplying the great-circle distances between the locations by .05 . Demand at a retailer was obtained by multiplying the 5 th column in the 88 -city dataset by .0001 . The fixed order cost at a warehouse was obtained by multiplying the 6th column in the 88-city dataset by 2.5 . For each retailer, the unit inventory cost and the fixed order cost were respectively $\$ 4.30$ and $\$ 2.10$, while for each warehouse, the unit inventory cost and the fixed order cost were respectively $\$ 2.60$ and $\$ 1.80$. The base planning period was taken as 365 days. DCs $=$ Number of open warehouses, Gap $=$ BestUpperBound - BestLowerBound, VOI = Value of Integration

\begin{tabular}{|c|c|c|c|c|c|c|c|}
\hline No. & $\beta_{\operatorname{trn}}$ & $\beta_{\text {inv }}$ & DCs & $\begin{array}{l}\text { Time } \\
\text { (sec.) }\end{array}$ & $\begin{array}{l}\text { Obtained } \\
\text { value }\end{array}$ & Gap & VOI \\
\hline 1 & 0.001 & 0.001 & 1 & 9.391 & 312002.081 & $4.075 \mathrm{E}-10$ & 0.0000 \\
\hline 2 & 0.001 & 0.010 & 1 & 10.842 & 316751.106 & $3.492 \mathrm{E}-10$ & 0.0000 \\
\hline 3 & 0.001 & 0.100 & 1 & 7.675 & 364241.359 & $1.746 \mathrm{E}-10$ & 0.0000 \\
\hline 4 & 0.001 & 1 & 1 & 7.441 & 839143.891 & $2.328 \mathrm{E}-10$ & 0.0000 \\
\hline 5 & 0.001 & 10 & 1 & 7.067 & 5588169.212 & $1.863 \mathrm{E}-09$ & 0.0000 \\
\hline 6 & 0.001 & 100 & 1 & 52.541 & 53078422.423 & $1.490 \mathrm{E}-08$ & 0.0000 \\
\hline 7 & 0.010 & 0.001 & 2 & 10.842 & 1960400.948 & $2.328 \mathrm{E}-10$ & 0.0000 \\
\hline 8 & 0.010 & 0.010 & 2 & 9.064 & 1965201.525 & $4.657 \mathrm{E}-10$ & 0.0000 \\
\hline 9 & 0.010 & 0.100 & 2 & 4.586 & 2013207.293 & $2.328 \mathrm{E}-10$ & 0.0000 \\
\hline 10 & 0.010 & 1 & 2 & 2.465 & 2493264.972 & $0.000 \mathrm{E}+00$ & 0.0000 \\
\hline 11 & 0.010 & 10 & 1 & 6.037 & 7293438.913 & $2.794 \mathrm{E}-09$ & 0.0055 \\
\hline 12 & 0.010 & 100 & 1 & 4.727 & 54783692.124 & $0.000 \mathrm{E}+00$ & 0.9417 \\
\hline 13 & 0.100 & 0.001 & 8 & 120.058 & 15848529.133 & $2.025 \mathrm{E}+04$ & -0.0270 \\
\hline 14 & 0.100 & 0.010 & 9 & 109.419 & 15849285.880 & $1.595 \mathrm{E}+04$ & 0.0000 \\
\hline 15 & 0.100 & 0.100 & 8 & 108.077 & 15903490.744 & $1.936 \mathrm{E}+04$ & -0.0247 \\
\hline 16 & 0.100 & 1 & 9 & 109.419 & 16399879.504 & $7.646 \mathrm{E}+03$ & 0.0155 \\
\hline 17 & 0.100 & 10 & 6 & 33.353 & 21326184.292 & $7.451 \mathrm{E}-09$ & 0.4908 \\
\hline 18 & 0.100 & 100 & 3 & 41.075 & 70017159.835 & $1.490 \mathrm{E}-08$ & 2.4252 \\
\hline 19 & 1 & 0.001 & 18 & 74.537 & 141735536.003 & $2.737 \mathrm{E}+02$ & 0.0000 \\
\hline 20 & 1 & 0.010 & 18 & 49.718 & 141740765.059 & $0.000 \mathrm{E}+00$ & 0.0000 \\
\hline 21 & 1 & 0.100 & 18 & 26.863 & 141793055.611 & $0.000 \mathrm{E}+00$ & 0.0000 \\
\hline 22 & 1 & 1 & 18 & 11.591 & 142315961.138 & $2.980 \mathrm{E}-08$ & 0.0000 \\
\hline 23 & 1 & 10 & 17 & 22.495 & 147568926.917 & $0.000 \mathrm{E}+00$ & -0.0162 \\
\hline 24 & 1 & 100 & 12 & 28.127 & 199923982.852 & $5.960 \mathrm{E}-08$ & -0.0442 \\
\hline 25 & 10 & 0.001 & 37 & 23.166 & 1380140957.773 & $9.537 \mathrm{E}-07$ & 0.0000 \\
\hline 26 & 10 & 0.010 & 37 & 51.340 & 1380146507.479 & $7.153 \mathrm{E}-07$ & 0.0000 \\
\hline 27 & 10 & 0.100 & 37 & 7.114 & 1380202004.539 & $2.384 \mathrm{E}-07$ & 0.0000 \\
\hline 28 & 10 & 1 & 37 & 6.365 & 1380756975.131 & $0.000 \mathrm{E}+00$ & 0.0000 \\
\hline 29 & 10 & 10 & 34 & 15.616 & 1386331075.279 & $2.384 \mathrm{E}-07$ & -0.0018 \\
\hline 30 & 10 & 100 & 22 & 16.037 & 1441817222.979 & $7.153 \mathrm{E}-07$ & -0.0009 \\
\hline 31 & 100 & 0.001 & 47 & 71.542 & 13731509847.074 & $1.907 \mathrm{E}-06$ & 0.0000 \\
\hline 32 & 100 & 0.010 & 47 & 4.930 & 13731515513.398 & $0.000 \mathrm{E}+00$ & 0.0000 \\
\hline 33 & 100 & 0.100 & 47 & 19.048 & 13731572176.638 & $0.000 \mathrm{E}+00$ & 0.0000 \\
\hline 34 & 100 & 1 & 47 & 5.242 & 13732138809.040 & $0.000 \mathrm{E}+00$ & 0.0000 \\
\hline 35 & 100 & 10 & 47 & 75.286 & 13737805133.056 & $5.722 \mathrm{E}-06$ & 0.0000 \\
\hline 36 & 100 & 100 & 47 & 15.912 & 13794526343.888 & $0.000 \mathrm{E}+00$ & -0.0004 \\
\hline
\end{tabular}


Table 4 Results for 150 retailers and 150 candidate warehouse locations chosen from the 150-city data set (retailers in cities $\{1-150\}$, candidate warehouse locations in cities $\{1-150\}$ ), for $\beta_{\operatorname{trn}} \in$ $\{0.001,0.01,0.1,1,10,100\}, \beta_{\text {inv }} \in\{0.001,0.01,0.1,1,10,100\}$. The plant is a location near Atlanta, Georgia, at longitude 84 and latitude 33. Per-unit shipping costs between the plant and warehouses were obtained by multiplying the great-circle distances between the locations by .04 , and per unit shipping costs between the warehouses and the retailers were obtained by multiplying the great-circle distances between the locations by .05 . Demand at a retailer was obtained by multiplying the 5 th column in the 150 -city dataset by .0001 . The fixed order cost at a warehouse was obtained by multiplying the 6th column in the 150 -city dataset by 2.5 . For each retailer, the unit inventory cost and the fixed order cost were respectively $\$ 4.30$ and $\$ 2.10$, while for each warehouse, the unit inventory cost and the fixed order cost were respectively $\$ 2.60$ and $\$ 1.80$. The base planning period was taken as 365 days. DCs $=$ Number of open warehouses, Gap $=$ BestUpperBound - BestLowerBound, VOI = Value of Integration

\begin{tabular}{|c|c|c|c|c|c|c|c|}
\hline No. & $\beta_{\operatorname{trn}}$ & $\beta_{\text {inv }}$ & DCs & $\begin{array}{l}\text { Time } \\
\text { (sec.) }\end{array}$ & $\begin{array}{l}\text { Obtained } \\
\text { value }\end{array}$ & Gap & VOI \\
\hline 1 & 0.001 & 0.001 & 1 & 459.205 & 491872.382 & $5.187 \mathrm{E}-05$ & 0.0000 \\
\hline 2 & 0.001 & 0.010 & 1 & 250.678 & 499184.009 & $1.746 \mathrm{E}-10$ & 0.0000 \\
\hline 3 & 0.001 & 0.100 & 1 & 299.272 & 572300.284 & $1.048 \mathrm{E}-09$ & 0.0000 \\
\hline 4 & 0.001 & 1 & 1 & 348.600 & 1303463.028 & $9.313 \mathrm{E}-10$ & 0.0000 \\
\hline 5 & 0.001 & 10 & 1 & 473.291 & 8615090.468 & $9.454 \mathrm{E}-01$ & 0.0000 \\
\hline 6 & 0.001 & 100 & 1 & 562.430 & 81731364.870 & $7.261 \mathrm{E}+01$ & 0.0000 \\
\hline 7 & 0.010 & 0.001 & 1 & 67.658 & 2661412.190 & $0.000 \mathrm{E}+00$ & 0.0000 \\
\hline 8 & 0.010 & 0.010 & 1 & 81.011 & 2668723.818 & $4.657 \mathrm{E}-10$ & 0.0000 \\
\hline 9 & 0.010 & 0.100 & 1 & 153.474 & 2741840.092 & $0.000 \mathrm{E}+00$ & 0.0000 \\
\hline 10 & 0.010 & 1 & 1 & 196.904 & 3473002.836 & $1.397 \mathrm{E}-09$ & 0.0000 \\
\hline 11 & 0.010 & 10 & 1 & 165.938 & 10784630.276 & $7.451 \mathrm{E}-09$ & 0.0000 \\
\hline 12 & 0.010 & 100 & 1 & 50.794 & 83900904.678 & $0.000 \mathrm{E}+00$ & 0.0000 \\
\hline 13 & 0.100 & 0.001 & 7 & 151.586 & 20339529.745 & $0.000 \mathrm{E}+00$ & 0.0000 \\
\hline 14 & 0.100 & 0.010 & 7 & 133.131 & 20347043.995 & $1.118 \mathrm{E}-08$ & 0.0000 \\
\hline 15 & 0.100 & 0.100 & 7 & 317.150 & 20422186.494 & $2.428 \mathrm{E}+00$ & 0.0000 \\
\hline 16 & 0.100 & 1 & 7 & 339.474 & 21173611.490 & $2.892 \mathrm{E}+02$ & 0.0000 \\
\hline 17 & 0.100 & 10 & 6 & 158.310 & 28740242.602 & $1.490 \mathrm{E}-08$ & -0.1823 \\
\hline 18 & 0.100 & 100 & 3 & 160.463 & 103748227.856 & $4.470 \mathrm{E}-08$ & 0.0792 \\
\hline 19 & 1 & 0.001 & 20 & 218.620 & 179924475.758 & $2.086 \mathrm{E}-07$ & 0.0000 \\
\hline 20 & 1 & 0.010 & 20 & 186.967 & 179932325.925 & $3.278 \mathrm{E}-07$ & 0.0000 \\
\hline 21 & 1 & 0.100 & 20 & 255.467 & 180010827.588 & $3.874 \mathrm{E}-07$ & 0.0000 \\
\hline 22 & 1 & 1 & 20 & 222.582 & 180795844.222 & $5.960 \mathrm{E}-08$ & 0.0000 \\
\hline 23 & 1 & 10 & 18 & 199.712 & 188699514.211 & $2.980 \mathrm{E}-08$ & -0.0284 \\
\hline 24 & 1 & 100 & 13 & 218.573 & 266773048.368 & $5.960 \mathrm{E}-08$ & 0.1404 \\
\hline 25 & 10 & 0.001 & 51 & 310.458 & 1733699031.838 & $1.082 \mathrm{E}-02$ & 0.0000 \\
\hline 26 & 10 & 0.010 & 51 & 150.432 & 1733707380.707 & $7.153 \mathrm{E}-07$ & 0.0000 \\
\hline 27 & 10 & 0.100 & 51 & 77.673 & 1733790869.406 & $7.153 \mathrm{E}-07$ & 0.0000 \\
\hline 28 & 10 & 1 & 51 & 335.075 & 1734625756.392 & $2.214 \mathrm{E}+01$ & 0.0000 \\
\hline 29 & 10 & 10 & 49 & 137.140 & 1743034093.294 & $4.768 \mathrm{E}-07$ & -0.0034 \\
\hline 30 & 10 & 100 & 32 & 80.169 & 1828811509.177 & $0.000 \mathrm{E}+00$ & -0.1284 \\
\hline 31 & 100 & 0.001 & 67 & 285.341 & 17208714121.291 & $2.289 \mathrm{E}-05$ & 0.0000 \\
\hline 32 & 100 & 0.010 & 67 & 275.935 & 17208722684.855 & $1.144 \mathrm{E}-05$ & 0.0000 \\
\hline 33 & 100 & 0.100 & 67 & 37.752 & 17208808320.494 & $0.000 \mathrm{E}+00$ & 0.0000 \\
\hline 34 & 100 & 1 & 67 & 243.580 & 17209664676.884 & $3.815 \mathrm{E}-06$ & 0.0000 \\
\hline 35 & 100 & 10 & 67 & 240.741 & 17218228240.787 & $7.629 \mathrm{E}-06$ & 0.0000 \\
\hline 36 & 100 & 100 & 59 & 239.727 & 17305227383.997 & $7.629 \mathrm{E}-06$ & -0.0079 \\
\hline
\end{tabular}


joint optimization algorithm is not guaranteed to find the optimal solution to the subproblems $S_{j}(\lambda)$; if it does not solve all such subproblems to optimality, then the "lower bound" obtained by Lagrangian relaxation is not necessarily a true lower bound. In contrast, the sequential optimization approach uses Lagrangian relaxation to solve a transportation-location problem. In this case, the subproblems $S_{j}(\lambda)$ can be solved to optimality, and as a result a it is more likely that a true lower bound will be obtained. Thus negative VOI highlight a fundamental tradeoff between the benefits gained from integration versus the costs associated with using a Lagrangian-relaxation-based algorithm that is not guaranteed to solve the associated subproblems to optimality.

It should be mentioned that it is possible to modify the joint optimization algorithm SolveMJIL (Algorithm 2) so that negative VOI do not arise. The modification is simply to first obtain a solution using SolveMJIL (Algorithm 2), then obtain a solution using the sequential optimization algorithm, and finally to take whichever of these solutions gives the smallest value for the objective function (15) as the solution to the MJIL problem. Since the value of this solution cannot be larger than the value obtained by sequential optimization alone, the VOI cannot be negative. While the resulting algorithm would perform no worse than either the current SolveMJIL or the sequential optimization algorithm, and would yield non-negative VOI, there is no guarantee that the resulting solution would be optimal.

Based on the results in Tables $1-4$, the region of the $\left(\beta_{\text {trn }}, \beta_{\text {inv }}\right)$ parameter space in which there appears to be a clear benefit to integration is a subset of

$$
\left\{\left(\beta_{\text {trn }}, \beta_{\text {inv }}\right): \beta_{\text {trn }} \leq 1, \beta_{\text {inv }} \text { large }\right\} .
$$

We therefore decided to investigate this region further for each data set by varying the values of the transportation cost weighting factor $\beta_{\text {trn }}$ and the inventory cost weighting factor $\beta_{\text {inv }}$ such that

$\beta_{\text {trn }} \in\{0.001,0.01,0.05,0.1,0.5,1\} \quad$ and $\quad \beta_{\text {inv }} \in\{100,150,225,337.5,506.25,759.375\}$.

These results, provided in Tables 5-8, reveal many positive VOI (along with some that are non-positive), demonstrating a clear benefit to integration over much of this region. The regions of the $\left(\beta_{\text {trn }}, \beta_{\text {inv }}\right)$ parameter space in which there is a benefit to integration will likely be problem-dependent.

Another pattern that emerged is that the number of opened warehouses tended to increase as the transportation cost weighting factor $\beta_{\text {trn }}$ was increased. This effect was particularly evident in Tables 1-4, which include larger values of $\beta_{\text {trn }}$ than Tables 5-8. An explanation for this behavior is that as transportation costs increase, the fixed cost of opening and operating a warehouse becomes less of a barrier to opening a warehouse.

\section{Conclusions and future research directions}

In this paper we developed a Lagrangian relaxation-based heuristic for solving an integrated supply chain model that simultaneously considers facility location decisions as well as inventory policies at warehouses and retailers. We observed that, while over much of the $\left(\beta_{\text {trn }}, \beta_{\text {inv }}\right)$ parameter space there was no discernible benefit to integration for these particular datasets and parameter values, over specific regions of this space there was a clear benefit to integration. We further observed that the number of opened warehouses tended to increase as the transportation cost weighting factor $\beta_{\text {trn }}$ was increased.

There are a number of ways in which these results can be extended: 
Table 5 Results for 11 retailers and 5 candidate warehouse locations chosen from the 49-city data set (retailers in cities $\{1-11\}$, candidate warehouse locations in cities $\{4,11,24,35,47\}$ ), for $\beta_{\operatorname{trn}} \in$ $\{0.001,0.01,0.05,0.1,0.5,1\}, \beta_{\text {inv }} \in\{100,150,225,337.5,506.25,759.375\}$. The plant is at a location near Atlanta, Georgia, at longitude 84 and latitude 33. Per-unit shipping costs between the plant and warehouses were obtained by multiplying the great-circle distances between the locations by .04 , and per unit shipping costs between the warehouses and the retailers were obtained by multiplying the great-circle distances between the locations by .05. Demand at a retailer was obtained by multiplying the 5th column in the 49-city dataset by .0001 . The fixed order cost at a warehouse was obtained by multiplying the 6th column in the 49-city dataset by 2.5 . For each retailer, the unit inventory cost and the fixed order cost were respectively $\$ 4.30$ and $\$ 2.10$, while for each warehouse, the unit inventory cost and the fixed order cost were respectively $\$ 2.60$ and $\$ 1.80$. The base planning period was taken as 365 days. DCs $=$ Number of open warehouses, Gap $=$ BestUpperBound - BestLowerBound, VOI = Value of Integration

\begin{tabular}{|c|c|c|c|c|c|c|c|c|}
\hline No. & $\beta_{\text {trn }}$ & $\beta_{\text {inv }}$ & DCs & $\begin{array}{l}\text { Time } \\
\text { (sec.) }\end{array}$ & $\begin{array}{l}\text { Obtained } \\
\text { value }\end{array}$ & Gap & VOI & $\begin{array}{l}\text { Optimal } \\
\text { value }\end{array}$ \\
\hline 1 & 0.001 & 100.000 & 1 & 0.047 & 8562526.023 & $1.863 \mathrm{E}-09$ & 0.0000 & 8562526.023 \\
\hline 2 & 0.001 & 150.000 & 1 & 0.078 & 12735646.737 & $0.000 \mathrm{E}+00$ & 0.0000 & 12735646.737 \\
\hline 3 & 0.001 & 225.000 & 1 & 0.062 & 18995327.808 & $0.000 \mathrm{E}+00$ & 0.0000 & 18995327.808 \\
\hline 4 & 0.001 & 337.500 & 1 & 0.125 & 28384849.415 & $3.725 \mathrm{E}-09$ & 0.0000 & 28384849.415 \\
\hline 5 & 0.001 & 506.250 & 1 & 0.140 & 42469131.825 & $0.000 \mathrm{E}+00$ & 0.0000 & 42469131.825 \\
\hline 6 & 0.001 & 759.375 & 1 & 0.281 & 63595555.440 & $7.451 \mathrm{E}-09$ & 0.0000 & 63595555.440 \\
\hline 7 & 0.01 & 100.000 & 1 & 0.031 & 8884723.311 & $1.863 \mathrm{E}-09$ & 0.0000 & 8884723.311 \\
\hline 8 & 0.01 & 150.000 & 1 & 0.047 & 13057844.025 & $0.000 \mathrm{E}+00$ & 0.0000 & 13057844.025 \\
\hline 9 & 0.01 & 225.000 & 1 & 0.062 & 19317525.096 & $3.725 \mathrm{E}-09$ & 0.0000 & 19317525.096 \\
\hline 10 & 0.01 & 337.500 & 1 & 0.062 & 28707046.703 & $0.000 \mathrm{E}+00$ & 0.0000 & 28707046.703 \\
\hline 11 & 0.01 & 506.250 & 1 & 0.078 & 42791329.113 & $0.000 \mathrm{E}+00$ & 0.0000 & 42791329.113 \\
\hline 12 & 0.01 & 759.375 & 1 & 0.078 & 63917752.727 & $1.490 \mathrm{E}-08$ & 0.0000 & 63917752.727 \\
\hline 13 & 0.05 & 100.000 & 1 & 0.047 & 10267650.841 & $0.000 \mathrm{E}+00$ & 3.1582 & 10267650.841 \\
\hline 14 & 0.05 & 150.000 & 1 & 0.047 & 14440771.555 & $1.863 \mathrm{E}-09$ & 3.6079 & 14440771.555 \\
\hline 15 & 0.05 & 225.000 & 1 & 0.218 & 20700452.626 & $0.000 \mathrm{E}+00$ & 3.9425 & 20700452.626 \\
\hline 16 & 0.05 & 337.500 & 1 & 0.140 & 30089974.233 & $3.725 \mathrm{E}-09$ & 4.1834 & 30089974.233 \\
\hline 17 & 0.05 & 506.250 & 1 & 0.359 & 44174256.643 & $2.025 \mathrm{E}+02$ & 4.3527 & 44174256.643 \\
\hline 18 & 0.05 & 759.375 & 2 & 0.484 & 68441978.742 & $3.143 \mathrm{E}+06$ & -0.3251 & 65300680.258 \\
\hline 19 & 0.10 & 100.000 & 1 & 0.016 & 11904627.672 & $1.863 \mathrm{E}-09$ & 1.4174 & 11904627.672 \\
\hline 20 & 0.1 & 150.000 & 1 & 0.047 & 16077748.386 & $3.725 \mathrm{E}-09$ & 2.2732 & 16077748.386 \\
\hline 21 & 0.1 & 225.000 & 1 & 0.031 & 22337429.457 & $0.000 \mathrm{E}+00$ & 2.9573 & 22337429.457 \\
\hline 22 & 0.1 & 337.500 & 1 & 0.031 & 31726951.064 & $0.000 \mathrm{E}+00$ & 3.4773 & 31726951.064 \\
\hline 23 & 0.1 & 506.250 & 1 & 0.078 & 45811233.474 & $0.000 \mathrm{E}+00$ & 3.8577 & 45811233.474 \\
\hline 24 & 0.1 & 759.375 & 1 & 0.047 & 66937657.089 & $0.000 \mathrm{E}+00$ & 4.1281 & 66937657.089 \\
\hline 25 & 0.5 & 100.000 & 3 & 0.000 & 23337424.895 & $3.725 \mathrm{E}-09$ & 0.0000 & 23337424.895 \\
\hline 26 & 0.5 & 150.000 & 3 & 0.000 & 27866301.308 & $0.000 \mathrm{E}+00$ & 0.0000 & 27866301.308 \\
\hline 27 & 0.5 & 225.000 & 3 & 0.062 & 34659615.928 & $0.000 \mathrm{E}+00$ & 0.0000 & 34659615.928 \\
\hline 28 & 0.5 & 337.500 & 2 & 0.109 & 44630208.831 & $0.000 \mathrm{E}+00$ & 0.4915 & 44630208.831 \\
\hline 29 & 0.5 & 506.250 & 1 & 0.000 & 58805778.450 & $0.000 \mathrm{E}+00$ & 2.2596 & 58805778.450 \\
\hline 30 & 0.5 & 759.375 & 1 & 0.000 & 79932202.065 & $1.490 \mathrm{E}-08$ & 3.9155 & 79932202.065 \\
\hline 31 & 1 & 100.000 & 3 & 0.000 & 36948346.963 & $0.000 \mathrm{E}+00$ & 0.0000 & 36948346.963 \\
\hline 32 & 1 & 150.000 & 3 & 0.000 & 41477223.376 & $0.000 \mathrm{E}+00$ & 0.0000 & 41477223.376 \\
\hline 33 & 1 & 225.000 & 3 & 0.000 & 48270537.996 & $0.000 \mathrm{E}+00$ & 0.0000 & 48270537.996 \\
\hline 34 & 1 & 337.500 & 3 & 0.000 & 58460509.926 & $0.000 \mathrm{E}+00$ & 0.0000 & 58460509.926 \\
\hline 35 & 1 & 506.250 & 3 & 0.016 & 73745467.820 & $0.000 \mathrm{E}+00$ & 0.0000 & 73745467.820 \\
\hline 36 & 1 & 759.375 & 1 & 0.016 & 96175383.285 & $0.000 \mathrm{E}+00$ & 0.5173 & 96142080.591 \\
\hline
\end{tabular}


Table 6 Results for 49 retailers and 49 candidate warehouse locations chosen from the 49-city data set (retailers in cities $\{1-49\}$, candidate warehouse locations in cities $\{1-49\}$ ), for $\beta_{\operatorname{trn}} \in$ $\{0.001,0.01,0.05,0.1,0.5,1\}, \beta_{\text {inv }} \in\{100,150,225,337.5,506.25,759.375\}$. The plant is at a location near Atlanta, Georgia, at longitude 84 and latitude 33. Per-unit shipping costs between the plant and warehouses were obtained by multiplying the great-circle distances between the locations by .04 , and per unit shipping costs between the warehouses and the retailers were obtained by multiplying the great-circle distances between the locations by .05 . Demand at a retailer was obtained by multiplying the 5th column in the 49-city dataset by .0001 . The fixed order cost at a warehouse was obtained by multiplying the 6th column in the 49-city dataset by 2.5 . For each retailer, the unit inventory cost and the fixed order cost were respectively $\$ 4.30$ and $\$ 2.10$, while for each warehouse, the unit inventory cost and the fixed order cost were respectively $\$ 2.60$ and $\$ 1.80$. The base planning period was taken as 365 days. DCs $=$ Number of open warehouses, Gap $=$ BestUpperBound - BestLowerBound, VOI $=$ Value of Integration

\begin{tabular}{|c|c|c|c|c|c|c|c|}
\hline No. & $\beta_{\operatorname{trn}}$ & $\beta_{\text {inv }}$ & DCs & $\begin{array}{l}\text { Time } \\
\text { (sec.) }\end{array}$ & $\begin{array}{l}\text { Obtained } \\
\text { value }\end{array}$ & Gap & VOI \\
\hline 1 & 0.001 & 100.000 & 1 & 1.388 & 31720476.352 & $0.000 \mathrm{E}+00$ & 0.0000 \\
\hline 2 & 0.001 & 150.000 & 1 & 1.685 & 47468686.404 & $1.490 \mathrm{E}-08$ & 0.0000 \\
\hline 3 & 0.001 & 225.000 & 1 & 2.402 & 71091001.482 & $0.000 \mathrm{E}+00$ & 0.0000 \\
\hline 4 & 0.001 & 337.500 & 1 & 3.557 & 106524474.099 & $0.000 \mathrm{E}+00$ & 0.0000 \\
\hline 5 & 0.001 & 506.250 & 1 & 6.131 & 159674683.024 & $0.000 \mathrm{E}+00$ & 0.0000 \\
\hline 6 & 0.001 & 759.375 & 1 & 8.003 & 239399996.411 & $5.960 \mathrm{E}-08$ & 0.0000 \\
\hline 7 & 0.01 & 100.000 & 1 & 1.794 & 32638982.591 & $0.000 \mathrm{E}+00$ & 0.0000 \\
\hline 8 & 0.01 & 150.000 & 1 & 6.287 & 48387192.643 & $1.490 \mathrm{E}-08$ & 0.0000 \\
\hline 9 & 0.01 & 225.000 & 1 & 0.967 & 72009507.720 & $0.000 \mathrm{E}+00$ & 0.0000 \\
\hline 10 & 0.01 & 337.500 & 1 & 1.061 & 107442980.337 & $1.490 \mathrm{E}-08$ & 0.0000 \\
\hline 11 & 0.01 & 506.250 & 1 & 2.262 & 160593189.262 & $0.000 \mathrm{E}+00$ & 0.0000 \\
\hline 12 & 0.01 & 759.375 & 1 & 2.496 & 240318502.649 & $5.960 \mathrm{E}-08$ & 0.0000 \\
\hline 13 & 0.05 & 100.000 & 1 & 0.234 & 36721232.540 & $1.490 \mathrm{E}-08$ & 2.0264 \\
\hline 14 & 0.05 & 150.000 & 1 & 0.780 & 52469442.592 & $7.451 \mathrm{E}-09$ & 2.6867 \\
\hline 15 & 0.05 & 225.000 & 1 & 0.889 & 76091757.669 & $1.490 \mathrm{E}-08$ & 3.1646 \\
\hline 16 & 0.05 & 337.500 & 1 & 1.092 & 111525230.286 & $0.000 \mathrm{E}+00$ & 3.5019 \\
\hline 17 & 0.05 & 506.250 & 1 & 1.076 & 164675439.211 & $0.000 \mathrm{E}+00$ & 3.7357 \\
\hline 18 & 0.05 & 759.375 & 1 & 0.920 & 244400752.598 & $0.000 \mathrm{E}+00$ & 3.8958 \\
\hline 19 & 0.10 & 100.000 & 3 & 5.803 & 41456373.509 & $0.000 \mathrm{E}+00$ & 0.1695 \\
\hline 20 & 0.1 & 150.000 & 2 & 4.789 & 57513461.829 & $2.980 \mathrm{E}-08$ & 0.7423 \\
\hline 21 & 0.1 & 225.000 & 1 & 0.421 & 81194570.105 & $0.000 \mathrm{E}+00$ & 1.6830 \\
\hline 22 & 0.1 & 337.500 & 1 & 1.248 & 116628042.722 & $0.000 \mathrm{E}+00$ & 2.4557 \\
\hline 23 & 0.1 & 506.250 & 1 & 1.045 & 169778251.647 & $0.000 \mathrm{E}+00$ & 3.0100 \\
\hline 24 & 0.1 & 759.375 & 1 & 1.061 & 249503565.034 & $2.980 \mathrm{E}-08$ & 3.3987 \\
\hline 25 & 0.5 & 100.000 & 6 & 2.761 & 73766781.604 & $2.980 \mathrm{E}-08$ & 0.7125 \\
\hline 26 & 0.5 & 150.000 & 4 & 0.515 & 90420915.658 & $0.000 \mathrm{E}+00$ & 1.2179 \\
\hline 27 & 0.5 & 225.000 & 4 & 0.998 & 115036293.380 & $1.490 \mathrm{E}-08$ & 2.0258 \\
\hline 28 & 0.5 & 337.500 & 4 & 3.557 & 151954798.213 & $0.000 \mathrm{E}+00$ & 2.7501 \\
\hline 29 & 0.5 & 506.250 & 4 & 4.633 & 207303994.956 & $0.000 \mathrm{E}+00$ & 3.3671 \\
\hline 30 & 0.5 & 759.375 & 2 & 5.039 & 289400438.709 & $0.000 \mathrm{E}+00$ & 4.1842 \\
\hline 31 & 1 & 100.000 & 8 & 0.998 & 112593155.815 & $0.000 \mathrm{E}+00$ & 0.1697 \\
\hline 32 & 1 & 150.000 & 8 & 4.914 & 129619641.268 & $0.000 \mathrm{E}+00$ & 0.4842 \\
\hline 33 & 1 & 225.000 & 6 & 2.839 & 154901908.397 & $0.000 \mathrm{E}+00$ & 0.9941 \\
\hline 34 & 1 & 337.500 & 4 & 2.153 & 192573020.176 & $0.000 \mathrm{E}+00$ & 1.6412 \\
\hline 35 & 1 & 506.250 & 4 & 4.087 & 247957620.051 & $0.000 \mathrm{E}+00$ & 2.7076 \\
\hline 36 & 1 & 759.375 & 4 & 4.774 & 331011123.971 & $5.960 \mathrm{E}-08$ & 3.6454 \\
\hline
\end{tabular}


Table 7 Results for 88 retailers and 88 candidate warehouse locations chosen from the 88-city data set (retailers in cities $\{1-88\}$, candidate warehouse locations in cities $\{1-88\}$ ), for $\beta_{\operatorname{trn}} \in$ $\{0.001,0.01,0.05,0.1,0.5,1\}, \beta_{\text {inv }} \in\{100,150,225,337.5,506.25,759.375\}$. The plant is at a location near Atlanta, Georgia, at longitude 84 and latitude 33. Per-unit shipping costs between the plant and warehouses were obtained by multiplying the great-circle distances between the locations by .04 , and per unit shipping costs between the warehouses and the retailers were obtained by multiplying the great-circle distances between the locations by .05 . Demand at a retailer was obtained by multiplying the 5 th column in the 88-city dataset by .0001 . The fixed order cost at a warehouse was obtained by multiplying the 6th column in the 88 -city dataset by 2.5 . For each retailer, the unit inventory cost and the fixed order cost were respectively $\$ 4.30$ and $\$ 2.10$, while for each warehouse, the unit inventory cost and the fixed order cost were respectively $\$ 2.60$ and $\$ 1.80$. The base planning period was taken as 365 days. DCs $=$ Number of open warehouses, Gap $=$ BestUpperBound - BestLowerBound, VOI $=$ Value of Integration

\begin{tabular}{|c|c|c|c|c|c|c|c|}
\hline No. & $\beta_{\text {trn }}$ & $\beta_{\text {inv }}$ & DCs & $\begin{array}{l}\text { Time } \\
\text { (sec.) }\end{array}$ & $\begin{array}{l}\text { Obtained } \\
\text { value }\end{array}$ & Gap & VOI \\
\hline 1 & 0.001 & 100.000 & 1 & 52.526 & 53078422.423 & $1.490 \mathrm{E}-08$ & 0.0000 \\
\hline 2 & 0.001 & 150.000 & 1 & 16.474 & 79461896.430 & $2.980 \mathrm{E}-08$ & 0.0000 \\
\hline 3 & 0.001 & 225.000 & 1 & 17.831 & 119037107.439 & $1.490 \mathrm{E}-08$ & 0.0000 \\
\hline 4 & 0.001 & 337.500 & 1 & 15.663 & 178399923.953 & $2.980 \mathrm{E}-08$ & 0.0000 \\
\hline 5 & 0.001 & 506.250 & 1 & 110.714 & 267444148.723 & $0.000 \mathrm{E}+00$ & 0.0000 \\
\hline 6 & 0.001 & 759.375 & 1 & 15.787 & 401010485.879 & $2.384 \mathrm{E}-07$ & 0.0000 \\
\hline 7 & 0.01 & 100.000 & 1 & 4.774 & 54783692.124 & $0.000 \mathrm{E}+00$ & 0.9417 \\
\hline 8 & 0.01 & 150.000 & 2 & 91.183 & 80963661.514 & $4.172 \mathrm{E}-07$ & 1.2423 \\
\hline 9 & 0.01 & 225.000 & 1 & 26.333 & 120742377.140 & $4.470 \mathrm{E}-08$ & 1.0203 \\
\hline 10 & 0.01 & 337.500 & 2 & 89.966 & 179972333.836 & $6.557 \mathrm{E}-07$ & 1.1164 \\
\hline 11 & 0.01 & 506.250 & 1 & 13.010 & 269149418.424 & $1.192 \mathrm{E}-07$ & 1.0563 \\
\hline 12 & 0.01 & 759.375 & 2 & 146.423 & 402691359.709 & $2.236 \mathrm{E}+05$ & 1.0721 \\
\hline 13 & 0.05 & 100.000 & 2 & 31.278 & 62094610.315 & $0.000 \mathrm{E}+00$ & 1.9244 \\
\hline 14 & 0.05 & 150.000 & 2 & 47.237 & 88455382.626 & $1.788 \mathrm{E}-07$ & 2.5742 \\
\hline 15 & 0.05 & 225.000 & 1 & 24.399 & 128320664.905 & $2.980 \mathrm{E}-08$ & 2.7868 \\
\hline 16 & 0.05 & 337.500 & 2 & 33.244 & 187503021.556 & $2.980 \mathrm{E}-08$ & 3.2747 \\
\hline 17 & 0.05 & 506.250 & 2 & 13.572 & 276615024.033 & $0.000 \mathrm{E}+00$ & 3.4878 \\
\hline 18 & 0.05 & 759.375 & 2 & 30.904 & 410051151.535 & $2.384 \mathrm{E}-07$ & 3.6925 \\
\hline 19 & 0.10 & 100.000 & 3 & 41.262 & 70017159.835 & $1.490 \mathrm{E}-08$ & 2.4252 \\
\hline 20 & 0.1 & 150.000 & 4 & 29.297 & 97372745.387 & $2.980 \mathrm{E}-08$ & 2.3397 \\
\hline 21 & 0.1 & 225.000 & 2 & 29.469 & 137023470.036 & $0.000 \mathrm{E}+00$ & 3.3068 \\
\hline 22 & 0.1 & 337.500 & 1 & 9.454 & 197081513.297 & $2.980 \mathrm{E}-08$ & 3.7185 \\
\hline 23 & 0.1 & 506.250 & 1 & 5.210 & 286125738.068 & $0.000 \mathrm{E}+00$ & 4.3923 \\
\hline 24 & 0.1 & 759.375 & 2 & 26.629 & 419348533.378 & $0.000 \mathrm{E}+00$ & 4.9528 \\
\hline 25 & 0.5 & 100.000 & 8 & 18.237 & 129231346.394 & $0.000 \mathrm{E}+00$ & 0.4719 \\
\hline 26 & 0.5 & 150.000 & 6 & 17.269 & 157117644.737 & $5.960 \mathrm{E}-08$ & 0.9119 \\
\hline 27 & 0.5 & 225.000 & 9 & 19.157 & 199875015.158 & $0.000 \mathrm{E}+00$ & 0.8702 \\
\hline 28 & 0.5 & 337.500 & 5 & 38.111 & 260300056.607 & $0.000 \mathrm{E}+00$ & 2.2704 \\
\hline 29 & 0.5 & 506.250 & 5 & 39.187 & 352190293.579 & $5.960 \mathrm{E}-08$ & 3.0987 \\
\hline 30 & 0.5 & 759.375 & 3 & 53.618 & 487216376.367 & $0.000 \mathrm{E}+00$ & 4.3569 \\
\hline 31 & 1 & 100.000 & 12 & 28.813 & 199923982.852 & $5.960 \mathrm{E}-08$ & -0.0442 \\
\hline 32 & 1 & 150.000 & 10 & 16.879 & 229956681.455 & $8.941 \mathrm{E}-08$ & -0.4657 \\
\hline 33 & 1 & 225.000 & 9 & 33.727 & 270457669.429 & $0.000 \mathrm{E}+00$ & 0.7408 \\
\hline 34 & 1 & 337.500 & 6 & 80.543 & 332832804.368 & $1.490 \mathrm{E}-06$ & 1.4998 \\
\hline 35 & 1 & 506.250 & 4 & 22.355 & 428439003.124 & $0.000 \mathrm{E}+00$ & 1.7343 \\
\hline 36 & 1 & 759.375 & 5 & 27.051 & 565073529.393 & $0.000 \mathrm{E}+00$ & 3.1612 \\
\hline
\end{tabular}


Table 8 Results for 150 retailers and 150 candidate warehouse locations chosen from the 150-city data set (retailers in cities $\{1-150\}$, candidate warehouse locations in cities $\{1-150\}$ ), for $\beta_{\operatorname{trn}} \in$ $\{0.001,0.01,0.05,0.1,0.5,1\}, \beta_{\text {inv }} \in\{100,150,225,337.5,506.25,759.375\}$. The plant is at a location near Atlanta, Georgia, at longitude 84 and latitude 33. Per-unit shipping costs between the plant and warehouses were obtained by multiplying the great-circle distances between the locations by .04 , and per unit shipping costs between the warehouses and the retailers were obtained by multiplying the great-circle distances between the locations by .05 . Demand at a retailer was obtained by multiplying the 5 th column in the 150-city dataset by .0001 . The fixed order cost at a warehouse was obtained by multiplying the 6th column in the 150 -city dataset by 2.5 . For each retailer, the unit inventory cost and the fixed order cost were respectively $\$ 4.30$ and $\$ 2.10$, while for each warehouse, the unit inventory cost and the fixed order cost were respectively $\$ 2.60$ and $\$ 1.80$. The base planning period was taken as 365 days. DCs $=$ Number of open warehouses, Gap $=$ BestUpperBound - BestLowerBound, VOI $=$ Value of Integration

\begin{tabular}{|c|c|c|c|c|c|c|c|}
\hline No. & $\beta_{\mathrm{trn}}$ & $\beta_{\text {inv }}$ & DCs & $\begin{array}{l}\text { Time } \\
\text { (sec.) }\end{array}$ & $\begin{array}{l}\text { Obtained } \\
\text { value }\end{array}$ & Gap & VOI \\
\hline 1 & 0.001 & 100.000 & 1 & 564.708 & 81731364.870 & $7.261 \mathrm{E}+01$ & 0.0000 \\
\hline 2 & 0.001 & 150.000 & 1 & 268.696 & 122351517.315 & $1.490 \mathrm{E}-08$ & 0.0000 \\
\hline 3 & 0.001 & 225.000 & 1 & 288.025 & 183281745.983 & $2.980 \mathrm{E}-08$ & 0.0000 \\
\hline 4 & 0.001 & 337.500 & 1 & 209.541 & 274677088.985 & $5.960 \mathrm{E}-08$ & 0.0000 \\
\hline 5 & 0.001 & 506.250 & 1 & 151.212 & 411770103.488 & $5.960 \mathrm{E}-08$ & 0.0000 \\
\hline 6 & 0.001 & 759.375 & 2 & 454.603 & 616026540.447 & $8.225 \mathrm{E}-06$ & 0.2245 \\
\hline 7 & 0.01 & 100.000 & 1 & 50.544 & 83900904.678 & $0.000 \mathrm{E}+00$ & 0.0000 \\
\hline 8 & 0.01 & 150.000 & 1 & 64.896 & 124521057.123 & $1.490 \mathrm{E}-08$ & 0.0000 \\
\hline 9 & 0.01 & 225.000 & 2 & 107.032 & 185404599.316 & $5.960 \mathrm{E}-08$ & 0.0252 \\
\hline 10 & 0.01 & 337.500 & 1 & 149.480 & 276846628.793 & $1.192 \mathrm{E}-07$ & 0.0000 \\
\hline 11 & 0.01 & 506.250 & 2 & 149.667 & 413545996.317 & $1.192 \mathrm{E}-07$ & 0.0952 \\
\hline 12 & 0.01 & 759.375 & 1 & 217.263 & 619579165.052 & $0.000 \mathrm{E}+00$ & 0.0000 \\
\hline 13 & 0.05 & 100.000 & 2 & 167.779 & 93096591.526 & $5.960 \mathrm{E}-08$ & 0.5399 \\
\hline 14 & 0.05 & 150.000 & 2 & 90.933 & 134005590.661 & $2.980 \mathrm{E}-08$ & 0.7209 \\
\hline 15 & 0.05 & 225.000 & 1 & 89.155 & 195093684.939 & $5.960 \mathrm{E}-08$ & 0.9927 \\
\hline 16 & 0.05 & 337.500 & 2 & 124.317 & 285922148.012 & $0.000 \mathrm{E}+00$ & 1.4677 \\
\hline 17 & 0.05 & 506.250 & 2 & 170.493 & 422711633.832 & $0.000 \mathrm{E}+00$ & 1.6652 \\
\hline 18 & 0.05 & 759.375 & 2 & 213.004 & 627813675.457 & $2.384 \mathrm{E}-07$ & 1.8135 \\
\hline 19 & 0.10 & 100.000 & 3 & 160.151 & 103748227.856 & $4.470 \mathrm{E}-08$ & 0.0792 \\
\hline 20 & 0.1 & 150.000 & 3 & 175.002 & 144271633.002 & $8.941 \mathrm{E}-08$ & 0.9042 \\
\hline 21 & 0.1 & 225.000 & 3 & 126.610 & 206718960.827 & $1.192 \mathrm{E}-07$ & 0.7140 \\
\hline 22 & 0.1 & 337.500 & 2 & 101.572 & 297902111.214 & $1.192 \mathrm{E}-07$ & 1.4169 \\
\hline 23 & 0.1 & 506.250 & 2 & 146.797 & 434992899.268 & $1.788 \mathrm{E}-07$ & 1.8442 \\
\hline 24 & 0.1 & 759.375 & 2 & 192.599 & 640473088.339 & $7.153 \mathrm{E}-07$ & 2.1672 \\
\hline 25 & 0.5 & 100.000 & 9 & 172.085 & 178028959.356 & $5.960 \mathrm{E}-08$ & 0.1314 \\
\hline 26 & 0.5 & 150.000 & 7 & 138.763 & 221314308.622 & $0.000 \mathrm{E}+00$ & 0.0040 \\
\hline 27 & 0.5 & 225.000 & 5 & 195.204 & 283462239.451 & $5.960 \mathrm{E}-08$ & 0.8648 \\
\hline 28 & 0.5 & 337.500 & 6 & 131.056 & 379562720.758 & $5.960 \mathrm{E}-08$ & 0.8527 \\
\hline 29 & 0.5 & 506.250 & 4 & 186.858 & 517284660.791 & $2.384 \mathrm{E}-07$ & 2.0962 \\
\hline 30 & 0.5 & 759.375 & 4 & 143.225 & 725642613.659 & $0.000 \mathrm{E}+00$ & 2.8221 \\
\hline 31 & 1 & 100.000 & 13 & 218.916 & 266773048.368 & $5.960 \mathrm{E}-08$ & 0.1404 \\
\hline 32 & 1 & 150.000 & 16 & 180.212 & 312670947.200 & $1.192 \mathrm{E}-07$ & -0.6113 \\
\hline 33 & 1 & 225.000 & 9 & 161.227 & 374386660.913 & $0.000 \mathrm{E}+00$ & 0.4784 \\
\hline 34 & 1 & 337.500 & 10 & 92.883 & 473053801.682 & $1.788 \mathrm{E}-07$ & 0.2645 \\
\hline 35 & 1 & 506.250 & 7 & 90.605 & 615337768.698 & $0.000 \mathrm{E}+00$ & 1.0007 \\
\hline 36 & 1 & 759.375 & 5 & 138.732 & 822957880.079 & $2.384 \mathrm{E}-07$ & 2.3481 \\
\hline
\end{tabular}


1. The model, which assumes the movement and storage of a single product, can be extended to consider multiple products.

2. Capacity constraints at the warehouses can be introduced. Stochastic capacity constraints can also be considered.

3. The single sourcing restriction can be relaxed to allow a single retailer to be supplied by more than one warehouse, which may be advantageous in capacitated models or in models with multiple products.

4. The assumption that lead times are negligible can be relaxed, and can be generalized to the case of stochastic lead times.

5. The inventory policy can be extended to include consideration of safety stock.

6. The model can be extended to allow lateral shipments between warehouses, which can result in substantial cost savings when the warehouses are owned by the same firm.

7. The assumption of direct shipments from warehouses to retailers can be relaxed, thus allowing routing decisions to be incorporated into the model, resulting in a model that combines location, inventory, and routing decisions.

8. The algorithm used to optimize the model can be improved.

Acknowledgements This work was supported by the Masdar Institute of Science and Technology (MIST). This support is gratefully acknowledged.

Open Access This article is distributed under the terms of the Creative Commons Attribution Noncommercial License which permits any noncommercial use, distribution, and reproduction in any medium, provided the original author(s) and source are credited.

\section{References}

Amiri, A. (2006). Designing a distribution network in a supply chain system: Formulation and efficient solution procedure. European Journal of Operational Research, 171, 567-576.

Axsäter, S. (2004). Simple evaluation of echelon stock $(R, Q)$ policies for two-level inventory systems. $I I E$ Transactions, 29, 661-669.

Barahona, F., \& Jensen, D. (1998). Plant location with minimum inventory. Mathematical Programming, 83, $101-111$.

Cavinato, J. L. (1992). A total cost/value model for supply chain competitiveness. Journal of Business Logistics, 13(2), 285-291.

Chan, F. T. S., Chung, S. H., \& Wadhwa, S. (2005). A hybrid genetic algorithm for production and distribution. Omega, 33(4), 345-355.

Chen, H., \& Chu, C. (2003). A Lagrangian relaxation approach for supply chain planning with order/setup costs and capacity constraints. Journal of Systems Science and Systems Engineering, 12(1), 98-110.

Chopra, S., \& Meindl, P. (2006). Supply chain management: strategy, planning, \& operations (3rd ed.). New York: Prentice-Hall.

Clark, A. J., \& Scarf, H. (1960). Optimal policies for a multi-echelon inventory problem. Management Science, 6(4), 475-490.

Daskin, M. S. (1995). Network and discrete location: models, algorithms, and applications. New York: Wiley.

Daskin, M. S., Coullard, C. R., \& Shen, Z.-J. M. (2002). An inventory-location model: formulation, solution algorithm and computational results. Annals of Operations Research, 110, 83-106.

Daskin, M. S., Snyder, L. V., \& Berger, R. T. (2005). Facility location in supply chain design. New York: Springer.

Eppen, G. D. (1979). Effects of centralization on expected costs in a multi-location newsboy problem. Management Science, 25(5), 498-501.

Erlebacher, S. J., \& Meller, R. D. (2000). The interaction of location and inventory in designing distribution systems. IIE Transactions, 32, 155-166.

Eskigun, E., Uzsoy, R., Preckel, P. V., Beaujon, G., Krishnan, S., \& Tew, J. D. (2005). Outbound supply chain network design with mode selection, lead times and capacitated vehicle distribution centers. European Journal of Operational Research, 165(1), 182-206. 
Fisher, M. L. (1981). The Lagrangian relaxation method for solving integer programming problems. Management Science, 27(1), 1-18.

Fisher, M. L. (1985). An applications-oriented guide to Lagrangian relaxation. Interfaces, 15, 10-21.

Gunasekaran, A., Patel, C., \& Tirtiroglu, E. (2001). Performance measures and metrics in a supply chain environment. International Journal of Operations \& Production Management, 21(1/2), 71-87.

Gunasekaran, A., Patel, C., \& McGaughey, R. E. (2004). A framework for supply chain performance measurement. International Journal of Production Economics, 87, 333-347.

Hindi, K. S., \& Pienkosz, K. (1999). Efficient solution of large scale, single-source, capacitated plant location problems. Journal of the Operational Research Society, 50, 268-274.

Jayaraman, V., \& Pirkul, H. (2001). Planning and coordination of production and distribution facilities for multiple commodities. European Journal of Operational Research, 133, 394-408.

Jayaraman, V., \& Ross, A. (2003). A simulated annealing methodology to distribution network design and management. European Journal of Operational Research, 144(3), 629-645.

Jones, T. C., \& Riley, D. W. (1987). Using inventory for competitive advantage through supply chain management. International Journal of Physical Distribution \& Logistics Management, 17, 94-104.

Min, H., Ko, H. J., \& Park, B. I. (2005). A Lagrangian relaxation heuristic for solving the multi-echelon, multi-commodity, close-loop supply chain network design problem. International Journal of Logistics Systems and Management, 1(4), 382-404.

Miranda, P. A., \& Garrido, R. A. (2006). A simultaneous inventory control and facility location model with stochastic capacity constraints. Networks and Spatial Economics, 6(1), 39-53.

Muckstadt, J. A., \& Roundy, R. O. (1987). Multi-item, one-warehouse, multi-retailer distribution systems. Management Science, 33(12), 1613-1621.

Ozsen, L., Coullard, C. R., \& Daskin, M. S. (2008). Capacitated warehouse location model with risk pooling. Naval Research Logistics, 55, 295-312.

Pirkul, H., \& Jayaraman, V. (1998). A multi-commodity, multi-plant, capacitated facility location problem: formulation and efficient heuristic solution. Computers \& Operations Research, 25, 869-878.

Putz, P. (2007). Subgradient optimization based Lagrangian relaxation and relax-and-cut approaches for the bounded-diameter minimum spanning tree problem. Master's thesis, Technical University of Vienna, October.

Romeijn, H. E., Shu, J., Teo, C.-P. (2007). Designing two-echelon supply networks. European Journal of Operations Research, 178, 449-462.

Roundy, R. (1985). 98\%-Effective integer-ratio lot-sizing for one-warehouse multi-retailer systems. Management Science, 31(11), 1416-1430.

Schwarz, L. B. (1973). A simple continuous review deterministic one-warehouse $n$-retailer inventory problem. Management Science, 19(5), 555-566.

Shen, Z.-J. M., Coullard, C. R., \& Daskin, M. S. (2003). A joint location-inventory model. Transportation Science, 37, 40-55.

Shiguemoto, A., \& Armentano, V. A. (2010). A tabu search procedure for coordinating production, inventory and distribution routing problems. International Transactions in Operational Research, 17(2), 179-195.

Shu, J. (2010). An efficient greedy heuristic for warehouse retailer network design optimization. Transportation Science, 44(2), 183-192.

Shu, J., Teo, C.-P., \& Shen, Z.-J. M. (2005). Stochastic transportation-inventory network design problem. Operations Research, 53(1), 48-60.

Silver, E. A., Pyke, D. F., \& Peterson, R. (1998). Inventory management and production planning and scheduling (3rd ed.). New York: Wiley.

Simchi-Levi, D., Kaminsky, P., \& Simchi-Levi, E. (2007). Designing \& managing the supply chain (3rd ed.). New York: McGraw-Hill/Irwin.

Sourirajan, K., Ozsen, L., \& Uzsoy, R. (2007). A single-product network design model with lead time and safety stock considerations. IIE Transactions, 39, 411-424.

Sourirajan, K., Ozsen, L., \& Uzsoy, R. (2009). A genetic algorithm for a single product network design model with lead time and safety stock considerations. European Journal of Operational Research, 197, 599-608.

Stevens, G. C. (1993). Integrating the supply chain. International Journal of Physical Distribution \& Logistics Management, 19(8), 3-8.

Svoronos, A., \& Zipkin, P. (1991). Evaluation of one-for-one replenishment policies for multiechelon inventory systems. Management Science, 37(1), 68-83.

Tanonkou, G.-A., Benyoucef, L., \& Xie, X. (2008). Design of Stochastic distribution networks using Lagrangian relaxation. IEEE Transactions on Automation Science and Engineering, 5(4), 597-608.

Teo, C.-P., \& Shu, J. (2004). Warehouse-retailer network design problem. Operations Research, 52(3), 396408. 
Teo, C.-P., Ou, J., \& Goh, M. (2001). Impact on inventory costs with consolidation of distribution centers. IIE Transactions, 33, 99-110.

Tsiakis, P., Shah, N., \& Pantelides, C. C. (2001). Design of multi-echelon supply chain networks under demand uncertainty. Industrial \& Engineering Chemistry Research, 40, 3585-3604.

Wee, H. M., \& Yang, P. C. (2004). The optimal and heuristic solutions of a distribution network. European Journal of Operational Research, 158(3), 626-632.

You, F., \& Grossman, I. E. (2008). Mixed-integer nonlinear programming models and algorithms for largescale supply chain design with stochastic inventory management. Industrial \& Engineering Chemistry Research, 47, 7802-7817.

You, F., \& Grossman, I. E. (2010). Integrated multi-echelon supply chain design with inventories under uncertainty: MINLP models, computational strategies. AIChE Journal, 56(2), 419-440. 